\title{
The Reward-Penalty Mechanism in a Closed-Loop Supply Chain with Asymmetric Information of the Third-Party Collector
}

\author{
Wenbin Wang $\mathbb{D}^{\mathrm{D}}$, Jia Lv, Ni An, Jie Guan, and Shiyuan Quan \\ School of Economics and Management, China University of Mining and Technology, Xuzhou 221116, China \\ Correspondence should be addressed to Wenbin Wang; wangwenbin818@126.com
}

Received 14 September 2021; Revised 18 November 2021; Accepted 30 November 2021; Published 21 December 2021

Academic Editor: Liu Zhi

Copyright (C) 2021 Wenbin Wang et al. This is an open access article distributed under the Creative Commons Attribution License, which permits unrestricted use, distribution, and reproduction in any medium, provided the original work is properly cited.

This paper investigates the reward-penalty mechanism (RPM) implemented by the government in a closed-loop supply chain (CLSC) with asymmetric information. The manufacturer produces and sells products to consumers, while the collection of waste electrical and electronic equipment (WEEE) is delegated to the third-party collector, the one who has private information about the collection effort level. An information screening contract for the manufacturer is put forward to obtain the private information from the third-party collector, which is composed of buy-back price and franchise fee. By utilizing principal-agent theory, two cases are mainly examined including the CLSC without the RPM and the CLSC with the RPM. The results demonstrate that (i) the information screening contract is effective in capturing the collector's collection effort level, (ii) raising the buy-back price to motivate the third-party collector is confirmed to perform well on enhancing the collection quantity from consumers, (iii) $\mathrm{H}$-type collector collects more WEEEs and earns more profits than L-type collector, and (iv) the RPM improves the collection quantity of the enterprise and reaps more environmental benefits. The numerical results verify the validity of the contract and the feasibility of the RPM.

\section{Introduction}

The problem of waste electrical and electronic equipment (WEEE) is becoming increasingly difficult for the government to manage $[1,2]$. As the gigantic benefits of remanufacturing in the field of environment and economy, the concept of the closed-loop supply chain (CLSC) has been extensively developed in recent years [3-6]. In addition, there exist growing enterprises to regulate strategies moderately in response to CLSC management. For example, Dell saves more costs than ever before in manufacturing and remanufacturing processes.

Additionally, many manufacturers have taken the initiative to undertake the responsibility for remanufacturing WEEE in the CLSC, while the collection of WEEE is delegated to third-party collectors who possess expertise and efficiency in the collection. Therefore, the third-party collector plays an important role in the collection process [7-10]. For instance, ReCellular Inc., the largest cellular telephone remanufacturer in the United States, outsources the collection operation to third-party collectors and provides applicable incentives to stimulate collecting used phones [11]. The third-party collector gathers WEEE from consumers and then sells reusable materials to the manufacturer, which prevents the environment from damaging by WEEE and reduces the cost of manufacturing products.

The enterprise makes appropriate decisions based on a large amount of information, such as historical information, online information, and forecast information [12, 13]. However, few enterprises are willing to share private information with others [14]. In particular, the company positioned at an unfair disadvantage in capturing information will spend more time and energy to obtain and examine the authenticity of the information. For instance, some delegated collectors may have more accurate information about the collection than manufacturers [15], as the collection effort level remains the private information of collectors and is rarely known by manufacturers. Under such circumstances, manufacturers hardly determine the buyback price for collectors who are accustomed to cheating 
manufacturers to earn more profits. Therefore, the information-poor company chooses to cooperate with other members in the supply chain and designs effective contracts to obtain the real asymmetric information.

Furthermore, the supervision of the government plays an essential role in the CLSC. In recent years, a number of environmental legislations have been implemented in many countries. In respect of collection and disposal of WEEE, China has promulgated the Circular Economy Promotion Law of the People's Republic of China, Administrative Measures for the Prevention and Control of Environmental Pollution by Electronic Waste, and Regulation on the Administration of the Recovery and Disposal of Waste Electrical and Electronic Products. On September 21, 2021, at the general debate of the 76th Session of the United Nations General Assembly, President Xi Jinping proposed a global development initiative of "Accelerating green and lowcarbon Transformation for Green Recovery and development" and reiterated that "China will strive to achieve carbon peak by 2030 and carbon neutral by 2060." In European Union, legislation such as the End-of-Life Vehicle Directive and the Waste Electrical and Electronic Equipment Directive is of course familiar [16]. Japan, Germany, and other countries have also formulated preferential tax policies, preferential price policies, garbage collection policies, and so on to improve the enthusiasm of enterprises and citizens to participate in recycling. By the end of 2005, more than 50 governments had implemented green procurement to guide market demand. The government's intervention guarantees the effective operation of CLSC. Besides, a series of environmental protection mechanisms have been offered, such as subsidies and tax exemption. Reward-penalty mechanism (RPM) is intended as the policy to encourage CLSC members to perform collection efficiently, which operates with the targeted collection quantity and the reward-penalty intensity. Particularly, in a two-stage CLSC, the manufacturer produces and sells products to consumers, and the collection of WEEE is deputed to the third-party collector. The third-party collector is assumed to choose different collection effort levels including high level and low level, all of which are the third-party collector's private information. Therefore, the third-party collector is divided into an H-type collector and an L-type collector. The manufacturer masters the probability of the third-party collector who adopts a high collection effort level. An information screening contract is designed to filter the collection effort information of the third-party collector. In addition, RPM is considered for the government to force the manufacturer to use collected materials as soon as possible. Under such circumstances, the manufacturer will receive rewards (penalties) if the collection quantity is more (less) than the targeted one. Specifically, we address the following research questions:

(i) Can the information screening contract help the manufacturer identify private information from the third-party collector?

(ii) How does the RPM impact the members of the CLSC with asymmetric information? (iii) How does the manufacturer increase the collection quantity collected by a third-party collector to avoid being punished by the government?

The remainder of this paper is organized as follows. Section 2 is an overview of the relevant literature. Section 3 gives the model descriptions, notations, and assumptions. In Section 4, Case 1 investigates the decision-making of the CLSC without RPM and Case 2 investigates the CLSC with RPM. We compare two cases to explore the impacts of RPM. Numerical studies are given to validate models in Section 5. Finally, Section 6 gives the conclusions, discusses managerial implications, and then presents future research directions.

\section{Literature Review}

Our paper mainly involves three aspects of literature: the third-party collection channel, the asymmetric information, and the government's intervention in the CLSC. We review the relevant literature in the following order. In Section 2.1, we address the literature on the third-party collection channel in the CLSC. Section 2.2 discusses the literature on asymmetric information in the supply chain. Literature concentrated on the government's intervention in the CLSC is displayed in Section 2.3.

2.1. The Third-Party Collection Channel in the CLSC. To enhance the efficiency of collection, a little literature focuses on the third-party collection channel in the CLSC. Savaskan et al. [7] solve the problem of reverse channel structure selection for recycling products. Huang et al. [8] conduct the optimal strategies of the CLSC by examining the competition between the retailer and the third-party collector. Centralized decisions and decentralized decisions are analyzed, respectively, to obtain managerial insights. The result demonstrates that dual-channel recovery is better than that in a single channel. Giovanni and Zaccour [17] verify whether a remanufacturer should manage the own waste collection or outsource collection to a collector. The result illustrates that the manufacturer outsources the product collection only when an outsourcer performs environmentally and operationally better. When outsourcing is convenient, the manufacturer gives priority to the retailer in the same conditions. Chu et al. [9] investigate that the thirdparty collector mode serving multiple manufacturers is better than the individual retailer-managed mode and the manufacturer-managed mode. With the concentrating operation in companies, like third-party logistics, most manufacturers outsource the collection operation to third-party collectors. Wan and Hong [18] analyze the optimal pricing and recycling decisions in CLSC including a manufacturer, a retailer, and two collectors. The transfer prices to two collectors are either uniform or different. The result reveals that the supply chain is more inclined to afford two collectors with different transfer prices. Wang et al. [19] establish two closed-loop supply chain models that have dual collection channels. The result draws that in any model, as consumers' preference for third-party collection channels increases, the third-party's optimal collection price always decreases. 
Zheng et al. [20] explore the reverse channel choice for the manufacturer and the design of coordination mechanisms in CLSCs in the midst of dual competitive sale channels. They consider three recycling channel structures: manufacturer collecting, retailer collecting, and third-party collecting structures. It can be seen that third-party collection has become one of the recycling channels widely studied by many scholars. Therefore, in this study, we consider that the manufacturer delegates the collection operation to a thirdparty collector and then buys collected materials that can be reused from this collector.

2.2. The Asymmetric Information in the Supply Chain. To obtain full information about the collection effort level and collection, cost remains extremely difficult for the manufacturer. Therefore, designing an appropriate contract is crucial for the manufacturer to obtain more private information and maximize profit. Corbett and Tang [21] present six scenarios where the consumers' cost structure is full and incomplete information in wholesale-pricing schemes, twopart linear schemes, and two-part nonlinear schemes, respectively. Zhang et al. [22] utilize a contract to coordinate a dual-channel supply chain under demand uncertainty and production cost uncertainty, respectively. They find that both the manufacturer and the retailer benefit from coordinating contracts when demand increases or production costs decrease. Wang et al. [15] consider the role of an information screening contract when the retailer shares the collection effort level information with the manufacturer in CLSC. Ma et al. [23] design the optimal contract for a supply chain where the manufacturer's social responsibility is asymmetric information. Zhang and Zhang [24] research a two-period supply chain where the supplier sells products through a retailer who has private market potential information. Wang et al. [25] design the contract mechanism for a supply chain consisting of one risk-neutral retailer and one risk-neutral supplier who has private production costs. In this study, we investigate asymmetric information of the third-party collector and design information screening contracts for the manufacturer to obtain that asymmetric information. Sun et al. [26] examine manufacturer encroachment with the cost reduction decision under asymmetric information and obtain some insights related to information management. Wang et al. [27] study how to achieve VMI supply chain coordination in an asymmetric information environment. The results indicate that the private information of the manufacturer and the retailer can coordinate the supply chain under the asymmetric information of bilateral information.

2.3. The Government's Intervention in the CLSC. The key purpose of our study is to investigate the impact of the government on the CLSC. Xie and Ma [28] claim that government as a supervisor plays a significant role to encourage collection operations in CLSC. Rahman and Subramanian [29] suggest that the government's legislation motivates the recycling operation in the computer industry. Wang et al. [30] take RPM into account to CLSC with a competitive dual collection channel and find that RPM improves the collection of waste products. Zand et al. [31] explore the optimal pricing and recycling in a two-stage closed-loop supply chain under the government limitation. The study demonstrates that the limitation benefits the recycling activities and the profit of the retailer at the expense of the manufacturer's profit. Chen and Akmalul 'Ulya [32] explore the green efforts of the manufacturer and the retailer in remanufacturing under the RPM. They find that the mechanism improves the green effort level and profits of both alike. Wang et al. [33] study the RPM for collection responsibility sharing in CLSC. The study reveals that it is optimal to impose the collection responsibility on the manufacturer, which is most beneficial to social welfare and collection rate. The government should impose higher reward-penalty intensity on the manufacturer. Besides, high reward-penalty intensity improves the social welfare level. Zhang et al. [34] study optimal pricing and remanufacturing mode in a closed-loop supply chain of WEEE under government fund policy. The results show that it can increase supply chain members' profits and promote the recycling and remanufacturing of used WEEE products when government fund policy parameters meet a certain range.

Previous literature contributes to the theory of CLSC. Table 1 reveals the main differences between our study and the existing literature, which concentrate on three aspects. First, literature has investigated the asymmetric information of the manufacturer, retailer, and consumer. For example, Wang et al. [15] study the asymmetric information of the retailer. However, the collector plays an increasingly significant role in the CLSC by virtue of professional collection ability. Therefore, we consider the asymmetric information about the collection effort level of the collector who is responsible for the collection operation and then analyze how to design an information screening contract for the manufacturer to capture the private information of the collector. Second, we further consider RPM to examine the influence of RPM implemented by the government on the manufacturer's decisions, which is mentioned in Wang et al. [15]. Finally, we develop the direct channel and assume that the manufacturer sells products to consumers directly, which is different from Wang et al. [30].

\section{Problem Formulation}

3.1. Model Description. The structure of CLSC is displayed in Figure 1. The solid line represents the direction of forwarding logistics and the dotted line indicates the direction of reverse logistics. Besides, some specific parameters are shown in Table 2.

In forward logistics, the manufacturer sells products at a retail price $p$ to customers directly. In reverse logistics, the third-party collector recycles WEEE from consumers with collection price $r_{i j}$. The manufacturer buys the collected components from a third-party collector with a buy-back price $b_{j}$ and charges the collector a franchise fee. Franchise fee here refers to a fee paid by the third-party collector to the manufacturer, so as to use the brand influence of manufacturing to improve their profits. In practice, the 
TABLE 1: Our work vs. the existing literature ${ }^{1}$.

\begin{tabular}{|c|c|c|c|c|c|}
\hline Authors & Supply chain structure & & $\begin{array}{l}\text { verse } \\
\text { annel } \\
\text { R C }\end{array}$ & Asymmetric information & Government intervention \\
\hline Savaskan et al. [7] & CLSC & $\checkmark$ & $\checkmark \checkmark$ & & \\
\hline Huang et al. [8] & $\begin{array}{l}\text { Dual collecting channel } \\
\text { CLSC }\end{array}$ & & $\checkmark \checkmark$ & & \\
\hline Giovanni and Zaccour [17] & CLSC & & $\checkmark$ & & \\
\hline Zhang et al. [22] & $\begin{array}{l}\text { Dual-channel supply } \\
\text { chain }\end{array}$ & & & $\begin{array}{c}\text { Demand uncertainty and production cost } \\
\text { uncertainty }\end{array}$ & \\
\hline Ma et al. [23] & Supply chain & & & $\begin{array}{c}\text { The social responsibility of the } \\
\text { manufacturer }\end{array}$ & \\
\hline Xie and $\mathrm{Ma}[28]$ & Reverse supply chain & & $\checkmark$ & & Subsidy \\
\hline $\begin{array}{l}\text { Rahman and Subramanian, } \\
\text { [29] }\end{array}$ & CLSC & $\checkmark$ & & & Subsidy \\
\hline Wang et al. [15] & CLSC & & $\checkmark$ & The collection effort level of the retailer & RPM \\
\hline Wang et al. [33] & CLSC & $\checkmark$ & & & $\mathrm{RPM}$ \\
\hline Our paper & CLSC & & $\checkmark$ & The collection effort level of the collector & RPM \\
\hline
\end{tabular}

${ }^{1} \mathrm{M}, \mathrm{R}$, and $\mathrm{C}$ represent the manufacturer, the retailer, and the collector, respectively.

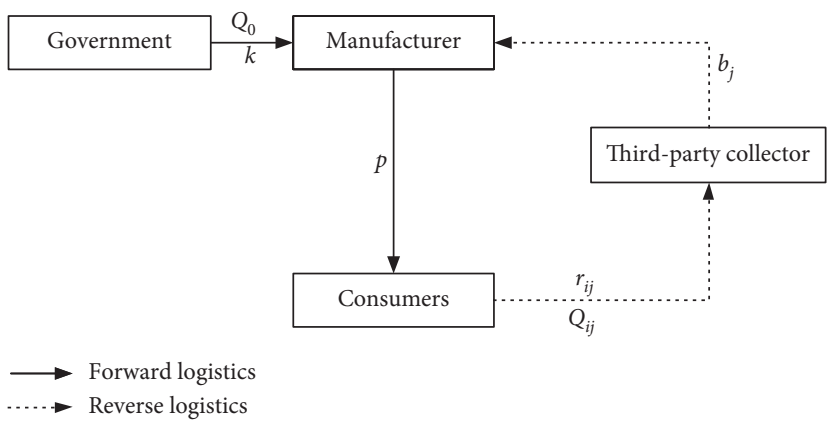

FIgURE 1: The structure of CLSC under the reward-penalty mechanism.

TABle 2: Notations.

\begin{tabular}{|c|c|}
\hline Symbol & Description \\
\hline \multicolumn{2}{|l|}{ Decision variables } \\
\hline$r_{i j}$ & Collection price when the collector chooses contract $G_{j}$, but the real collection effort level is $e_{i}, i, j \in\{H, L\}$ \\
\hline$b_{j}$ & Buy-back price when the collector chooses contract $G_{j}, j \in\{H, L\}$ \\
\hline$T_{j}$ & Franchise fee when the collector chooses contract $G_{j}, j \in\{H, L\}$ \\
\hline \multicolumn{2}{|r|}{ (25 } \\
\hline$c_{n}$ & Manufacturer's production cost of using new components and materials \\
\hline$c_{r}$ & Manufacturer's production cost of using recycled components \\
\hline$\Delta$ & Unit saved cost, $\Delta=c_{n}-c_{r}$ \\
\hline$e_{i}$ & Collection effort level of the third-party collector, $i \in\{H, L\}, 0<e_{L}<e_{H}$ \\
\hline$k$ & The reward-penalty intensity, $k>0$ \\
\hline$Q_{0}$ & The target collection quantity \\
\hline$v$ & The probability of third-party collector who adopts $e_{H}, 0<v<1$ \\
\hline$\pi_{r}^{0}$ & The reserved profit \\
\hline$p$ & Unit retail price \\
\hline \multicolumn{2}{|l|}{ Derived functions } \\
\hline$E\left(\pi_{m j}\right)$ & The expected profit of manufacturer when collector chooses contract $G_{j}, j \in\{H, L\}$ \\
\hline$E\left(\pi_{r i j}\right)$ & The expected profit of $i$ type collector choosing contract $G_{j}, i, j \in\{H, L\}$ \\
\hline$Q_{i j}$ & Collection quantity of $i$ type collector choosing contract $G_{j}, i, j \in\{H, L\}$ \\
\hline & Information screening contract, i.e., $\left\{G_{H}\left(b_{H}, T_{H}\right), G_{L}\left(b_{L}, T_{L}\right)\right\}$ \\
\hline \multicolumn{2}{|r|}{ 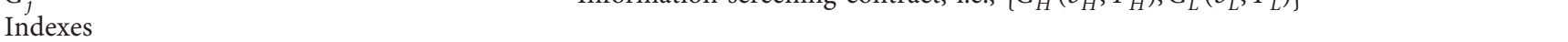 } \\
\hline Subscript $H$ & The type of high collection effort level \\
\hline Subscript $L$ & The type of low collection effort level \\
\hline Superscript $*$ and $* *$ & The optimal decision \\
\hline
\end{tabular}


franchise fee is a common phenomenon, such as franchise stores [17]. Besides, the collection effort level of the thirdparty collector is segmented into $\mathrm{H}$-type and L-type, which is asymmetric private information for the manufacturer. We design an information screening contract for the manufacturer to obtain private information. The information screening contract is expressed as $\left\{G_{H}\left(b_{H}, T_{H}\right)\right.$, $\left.G_{L}\left(b_{L}, T_{L}\right)\right\}$, which is composed of buy-back price and franchise fee.

3.2. Model Assumptions. The following assumptions are made for developing the model of CLSC.

(i) We consider the optimization problem in singlecycle CLSC where the third-party collector has private information and the information of other members is symmetrical.

(ii) The products have the same quality and retail price whether using new materials or recycled components. These products correspond with the leasing office's equipment, such as photocopiers and printers $[33,35,36]$.

(iii) We have the priority of using recycled components in the production, while new materials are used only when recycled components are exhausted because of the lower cost of recycled components $[1,37]$.

(iv) The unit cost of using new materials is larger than the unit cost of using recycled components; i.e., $\Delta=c_{n}-c_{r}>0[9,38]$.

(v) The manufacturer and third-party collector are risk neutral; they all devote themselves to achieving the optimal profits $[2,7,38]$.

(vi) The cost of collection effort level is a quadratic function. The function is given by $c\left(e_{i}\right)=e_{i}^{2} / 4$, and $i, j \in\{H, L\}$. Besides, we have $c^{\prime}\left(e_{i}\right)>0$ and $c^{\prime \prime}\left(e_{i}\right)>0[1,7,39]$.

(vii) The market demand is $D=\phi-p+\theta$, where $\phi$ indicates the market size. In addition, $\theta$ is the impact of random factors in the market and its distribution function is $U(0, a)(a>0)$. Besides, the probability density function is $f(\cdot)$ and the probability distribution function is $F(\cdot)$. Further, the probability density function can be expressed as $f(x)=\left\{\begin{array}{ll}1 / a, & x \in(0, a), \\ 0, & \text { other, }\end{array}\right.$, where " $x$ " represents the range of values of $\theta$ [40].

(viii) The quantity of the collected WEEE is a linear function of both the collection effort level and the collection price, i.e., $Q_{i j}=e_{i}+r_{i j}$ [15], $0<e_{L}<e_{H}$.

\section{The Model}

4.1. The CLSC without RPM (Case 1). In this section, we consider a benchmark model where the manufacturer is responsible for producing and selling products. The thirdparty collector, who has private information of collection effort level, is in charge of collecting used products from consumers. An information screening contract is designed for the manufacturer to obtain the private information of the third-party collector. Based on assumptions in Section 3.2, we develop the model as follows.

When the collector adopts an information screening contract $G_{H}$, the expected profit of the manufacturer can be written as follows:

$$
\begin{aligned}
E\left(\pi_{m H}\right)= & \int_{0}^{Z_{H}}(\phi-p+x)\left(p-c_{r}\right) f(x) d x \\
& +\int_{Z_{H}}^{a}\left(\phi-p+x-e_{H}-r_{H H}\right)\left(p-c_{n}\right) f(x) d x \\
& +\int_{Z_{H}}^{a}\left(e_{H}+r_{H H}\right)\left(p-c_{r}\right) f(x) d x-b_{H}\left(e_{H}+r_{H H}\right)+T_{H} .
\end{aligned}
$$

In equation (1), $Z_{H}=e_{H}+r_{H H}-\phi+p$. When $0<x \leq Z_{H}$, the recycled components satisfy the needs of production. When $Z_{H}<x<a$, both the recycled materials and new materials satisfy the needs of production.

When the collector selects contract $G_{L}$, the expected profit of the manufacturer is represented by

$$
\begin{aligned}
E\left(\pi_{m L}\right)= & \int_{0}^{Z_{L}}(\phi-p+x)\left(p-c_{r}\right) f(x) d x \\
& +\int_{Z_{L}}^{a}\left(\phi-p+x-e_{L}-r_{L L}\right)\left(p-c_{n}\right) f(x) d x \\
& +\int_{Z_{L}}^{a}\left(e_{L}+r_{L L}\right)\left(p-c_{r}\right) f(x) d x-b_{L}\left(e_{L}+r_{L L}\right)+T_{L} .
\end{aligned}
$$

In equation (2), when $0<x \leq Z_{L}$, the production is fulfilled by utilizing the recycled materials. Otherwise, when $Z_{L}<x<a$, the production is satisfied by using recycled components and new materials jointly.

If the collector exerts collection effort $e_{H}$ and chooses contract $G_{H}$, the expected profit of the collector is

$$
E\left(\pi_{r H H}\right)=\left(b_{H}-r_{H H}\right)\left(e_{H}+r_{H H}\right)-\frac{e_{H}^{2}}{4}-T_{H} .
$$

If the collector adopts collection effort $e_{H}$ and chooses contract $G_{L}$, the expected profit of the collector is denoted by

$$
E\left(\pi_{r H L}\right)=\left(b_{L}-r_{H L}\right)\left(e_{H}+r_{H L}\right)-\frac{e_{H}^{2}}{4}-T_{L} .
$$

When the collector selects collection effort $e_{L}$ and adopts contract $G_{L}$, the profit of the collector is given as

$$
E\left(\pi_{r L L}\right)=\left(b_{L}-r_{L L}\right)\left(e_{L}+r_{L L}\right)-\frac{e_{L}^{2}}{4}-T_{L} .
$$

As the collector is collection effort $e_{L}$ but chooses contract $G_{H}$, then collector's expected profit is

$$
E\left(\pi_{r L H}\right)=\left(b_{H}-r_{L H}\right)\left(e_{L}+r_{L H}\right)-\frac{e_{L}^{2}}{4}-T_{H} .
$$

In this case, the objective function and constraints are expressed as 


$$
\max E\left(\pi_{m}\right)=v E\left(\pi_{m H}\right)+(1-v) E\left(\pi_{m L}\right)
$$

s.t.

$$
\begin{gathered}
r_{H H}^{*}=\arg \max E\left(\pi_{r H H}\right), \\
r_{L L}^{*}=\arg \max E\left(\pi_{r L L}\right),
\end{gathered}
$$

$$
\text { (IR) } E\left(\pi_{r L L}\right) \geq \pi_{r}^{0}
$$

$$
\text { (IR) } E\left(\pi_{r H H}\right) \geq \pi_{r}^{0} \text {, }
$$

$$
\text { (IC) } E\left(\pi_{r H H}\right) \geq E\left(\pi_{r H L}\right) \text {, }
$$

$$
\text { (IC) } E\left(\pi_{r L L}\right) \geq E\left(\pi_{r L H}\right) \text {. }
$$

Equations (10) and (11) are participation constraints that guarantee that the expected profit of the collector is higher than the case without constraints. Equations (12) and (13) are incentive compatibility constraints to avoid the false information provided by the collector.

With the Lagrange multiplier method, the optimization problem and the optimal results can be derived as follows:

$$
\begin{aligned}
b_{H}^{*} & =\frac{\Delta\left(2 a-e_{H}+2 \phi-2 p\right)}{\Delta+2 a}, \\
b_{L}^{*} & =\frac{\Delta\left(2 a-e_{L}+2 \phi-2 p\right)-2 a e_{L}}{\Delta+2 a}+\frac{2 a\left(e_{L}-v e_{H}\right)}{(1-v)(\Delta+2 a)}, \\
T_{L}^{*} & =\frac{\left(b_{L}^{*}+e_{L}\right)^{2}-e_{L}^{2}-\pi_{r}^{0},}{4} \\
T_{H}^{*} & =\frac{\left(b_{H}^{*}+e_{H}\right)^{2}-\left(b_{L}^{*}+e_{H}\right)^{2}+\left(b_{L}^{*}+e_{L}\right)^{2}-e_{L}^{2}}{4}-\pi_{r}^{0}, \\
r_{H H}^{*} & =\frac{b_{H}^{*}-e_{H}}{2}, \\
r_{L L}^{*} & =\frac{b_{L}^{*}-e_{L}}{2} .
\end{aligned}
$$

The solving process is shown in the Appendix. With the optimal outcomes, we have Proposition 1.

\section{Proposition 1}

(i) In the information screening contract $G_{H}$, the optimal decisions are $b_{H}^{*}=\Delta\left(2 a-e_{H}+2 \phi-2 p\right)$ $/(\Delta+2 a)$ and $T_{H}^{*}=\left(\left(\left(b_{H}^{*}+e_{H}\right)^{2}-\left(b_{L}^{*}+e_{H}\right)^{2}\right.\right.$ $\left.\left.+\left(b_{L}^{*}+e_{L}\right)^{2}-e_{L}^{2}\right) /(4)\right)-\pi_{r}^{0}$

(ii) In the information screening contract $G_{L}$, the optimal decisions are $b_{L}^{*}=\left(\left(\Delta\left(2 a-e_{L}+2 \phi-2 p\right)-2 a e_{L}\right) /\right.$ $(\Delta+2 a))+\left(\left(2 a\left(e_{L}-v e_{H}\right)\right) /((1-v)(\Delta+2 a))\right), T_{L}^{*}$ $=\left(\left(\left(b_{L}^{*}+e_{L}\right)^{2}-e_{L}^{2}\right) /(4)\right)-\pi_{r}^{0}$

(iii) The optimal collection prices are $r_{H H}^{*}=$ $\left(b_{H}^{*}-e_{H}\right) /(2)$ and $r_{L L}^{*}=\left(b_{L}^{*}-e_{L}\right) /(2)$

Proposition 1 gives the optimal information screening contract which includes the optimal buy-back price and the franchise fee. Such a contract can ensure the manufacturer obtains the collector's collection effort level effectively in CLSC.

Substituting the optimal collection prices into $Q_{i j}=e_{i}+r_{i j}$, we have the optimal collection quantities. By comparing the collection quantities of different types, we can obtain Proposition 2.

Proposition 2. The H-type collector collects higher quantities than the L-type collector; i.e., $Q_{H H}^{*}>Q_{L L}^{*}$.

Proof. By calculation, we have $Q_{H H}^{*}-Q_{L L}^{*}=(1 / 2)\left[\left(e_{H}-\right.\right.$ $\left.\left.e_{L}\right)+\left(b_{H}^{*}-b_{L}^{*}\right)\right]=\left(\left(\left(e_{H}-e_{L}\right) a\right) /((1-v)(\Delta+2 a))\right)$. With $e_{H}>e_{L}$ and $a>0$, we can easily obtain $Q_{H H}^{*}>Q_{L L}^{*}$.

Proposition 2 implies that the H-type collector makes more effort to collect WEEE and then she can reap more WEEE than the L-type collector. We can further obtain that the collection quantity increases in the probability of the third-party collector being an H-type, which also indicates that an H-type collector will pay more attention to the collection.

Consider that many governments are endeavoring to regulate WEEE and prevent pollution. We next take a government's management into account in the CLSC with asymmetric information.

4.2. The CLSC with RPM (Case2). In this section, the government implements RPM on the manufacturer in CLSC. The government rewards the manufacturer when the collection target is overfulfilled otherwise, the manufacturer will be penalized.

When the collector adopts contract $G_{H}$, the expected profit of the manufacturer is

$$
\begin{aligned}
E\left(\pi_{m H}\right)= & \int_{0}^{Z_{H}}(\phi-p+x)\left(p-c_{r}\right) f(x) d x+\int_{Z_{H}}^{a}\left(\phi-p+x-e_{H}-r_{H H}\right)\left(p-c_{n}\right) f(x) d x \\
& +\int_{Z_{H}}^{a}\left(e_{H}+r_{H H}\right)\left(p-c_{r}\right) f(x) d x-b_{H}\left(e_{H}+r_{H H}\right)+T_{H}+k\left(e_{H}+r_{H H}-Q_{0}\right) .
\end{aligned}
$$


In equation (20), $Z_{H}=e_{H}+r_{H H}-\phi+p$. Enough WEEE materials satisfy the needs of production when $0<x \leq Z_{H}$. When $Z_{H}<x<a$, manufacturer utilizes recycled components and new materials for meeting production.

Similarly, if the collector chooses contract $G_{L}$, the expected profit of the manufacturer is expressed as

$$
\begin{aligned}
E\left(\pi_{m L}\right)= & \int_{0}^{Z_{L}}(\phi-p+x)\left(p-c_{r}\right) f(x) d x \\
& +\int_{Z_{L}}^{a}\left(\phi-p+x-e_{L}-r_{L L}\right)\left(p-c_{n}\right) f(x) d x \\
& +\int_{Z_{L}}^{a}\left(e_{L}+r_{L L}\right)\left(p-c_{r}\right) f(x) d x-b_{L}\left(e_{L}+r_{L L}\right) \\
& +T_{L}+k\left(e_{L}+r_{L L}-Q_{0}\right) .
\end{aligned}
$$

In equation (21), $Z_{L}=e_{L}+r_{L L}-\phi+p$. When $0<x \leq Z_{L}$, the needs of production are satisfied with recycled components. When $Z_{L}<x<a$, the needs of production are met by using recycled components and new materials jointly.

If the collection effort of collector is $e_{H}$ and the collector chooses contract $G_{H}$, the expected profit of collector is

$$
E\left(\pi_{r H H}\right)=\left(b_{H}-r_{H H}\right)\left(e_{H}+r_{H H}\right)-\frac{e_{H}^{2}}{4}-T_{H} .
$$

When the collector adopts collection effort $e_{H}$ but chooses contract $G_{L}$, the expected profit of collector is denoted as

$$
E\left(\pi_{r H L}\right)=\left(b_{L}-r_{H L}\right)\left(e_{H}+r_{H L}\right)-\frac{e_{H}^{2}}{4}-T_{L} .
$$

If the collector's collection effort is $e_{L}$ and the collector selects contract $G_{L}$, the expected profit of the collector is expressed as

$$
E\left(\pi_{r L L}\right)=\left(b_{L}-r_{L L}\right)\left(e_{L}+r_{L L}\right)-\frac{e_{L}^{2}}{4}-T_{L} .
$$

If the collector's collection effort is $e_{L}$ but the collector chooses contract $G_{H}$, the expected profit of collector is

$$
E\left(\pi_{r L H}\right)=\left(b_{H}-r_{L H}\right)\left(e_{L}+r_{L H}\right)-\frac{e_{L}^{2}}{4}-T_{H} .
$$

In the CLSC under RPM, the objective function and constraints are expressed as

$$
\max E\left(\pi_{m}\right)=v E\left(\pi_{m H}\right)+(1-v) E\left(\pi_{m L}\right)
$$

s.t.

$$
\begin{aligned}
& r_{H H}^{* *}=\arg \max E\left(\pi_{r H H}\right), \\
& r_{L L}^{* *}=\arg \max E\left(\pi_{r L L}\right), \\
&(\mathrm{IR}) E\left(\pi_{r L L}\right) \geq \pi_{r}^{0}, \\
&(\mathrm{IR}) E\left(\pi_{r H H}\right) \geq \pi_{r}^{0}, \\
&(\mathrm{IC}) E\left(\pi_{r H H}\right) \geq E\left(\pi_{r H L}\right), \\
&(\mathrm{IC}) E\left(\pi_{r L L}\right) \geq E\left(\pi_{r L H}\right) .
\end{aligned}
$$

Equations (29) and (30) are participation constraints to ensure that the collector accepts the contract. Equations (31) and (32) are incentive compatibility constraints. The incentive compatibility constraints enable the collector to share the right collection effort level information.

Solving this model with the Lagrange multiplier method, we obtain

$$
\begin{aligned}
b_{H}^{* *} & =\frac{\Delta\left(2 a-e_{H}+2 \phi-2 p\right)+2 a k}{\Delta+2 a}, \\
b_{L}^{* *} & =\frac{\Delta\left(2 a-e_{L}+2 \phi-2 p\right)+2 a\left(k-e_{L}\right)}{\Delta+2 a}+\frac{2 a\left(e_{L}-v e_{H}\right)}{(1-v)(\Delta+2 a)}, \\
T_{L}^{* *} & =\frac{\left(b_{L}^{* *}+e_{L}\right)^{2}-e_{L}^{2}}{4}-\pi_{r}^{0}, \\
T_{H}^{* *} & =\frac{\left(b_{H}^{* *}+e_{H}\right)^{2}-\left(b_{L}^{* *}+e_{H}\right)^{2}+\left(b_{L}^{* *}+e_{L}\right)^{2}-e_{L}^{2}-\pi_{r}^{0},}{4} \\
r_{H H}^{* *} & =\frac{b_{H}^{* *}-e_{H}}{2}, \\
r_{L L}^{* *} & =\frac{b_{L}^{* *}-e_{L}}{2} .
\end{aligned}
$$


The solving process is shown in the Appendix. With the optimal results above, we give Proposition 3.

\section{Proposition 3}

(a) Under the RPM, the optimal information screening contract $G_{H}$ is given by $b_{H}^{* *}=\left(\Delta\left(2 a-e_{H}\right.\right.$ $+2 \phi-2 p)+2 a k) /(\Delta+2 a), T_{H}^{* *}=\left(\left(\left(b_{H}^{* *}+e_{H}\right)^{2}-\right.\right.$ $\left.\left.\left(b_{L}^{* *}+e_{H}\right)^{2}+\left(b_{L}^{* *}+e_{L}\right)^{2}-e_{L}^{2}\right) /(4)\right)-\pi_{r}^{0}$

(b) Under the RPM, the optimal information screening contract $G_{L}$ is given by $b_{L}^{* *}=\left(\left(\Delta\left(2 a-e_{L}+2 \phi-\right.\right.\right.$ $\left.\left.2 p)+2 a\left(k-e_{L}\right)\right) /(\Delta+2 a)\right)+\left(\left(2 a\left(e_{L}-v e_{H}\right)\right) /((1\right.$ $-v)(\Delta+2 a))), T_{L}^{* *}=\left(\left(\left(b_{L}^{* *}+e_{L}\right)^{2}-e_{L}^{2}\right) /(4)\right)-\pi_{r}^{0}$

Proposition 3 gives the optimal information screening contract which includes the optimal buy-back price and the franchise fee in CLSC with RPM. In this case, the information screening contract also ensures that the manufacturer obtains the collector's private information effectively.

4.3. Comparison of the Equilibrium Solutions. In this section, we compare the optimal results with and without RPM to find managerial insights. The conclusions are shown in the following propositions.

Proposition 4. Under the RPM, the manufacturer increases the buy-back price, and the collector raises the collection price and gets a higher collection quantity.

Proof. Comparing equation (33) with equation (14), we have $b_{H}^{*}{ }^{*}-b_{H}^{*}=((2 a k) /(\Delta+2 a))>0$. Similarly, we get $b_{L}^{*}{ }^{*}-$ $b_{L}^{*}=((2 a k) /(\Delta+2 a))>0$ by comparing equation (34) with equation (15). Based on the results of comparisons, the buyback price is enhanced when the government implements RPM. Comparing equation (37) with equation (18), we obtain $r_{H H}^{* *}-r_{H H}^{*}=\left(\left(b_{H}^{* *}-b_{H}^{*}\right) /(2)\right)>0$. Similarly, we have $r_{L L}^{* *}-r_{L L}^{*}=\left(\left(b_{L}^{* *}-b_{L}^{*}\right) /(2)\right)>0$. Besides, comparing the collection quantity of different cases, we obtain $Q_{H H}^{* *}-$ $Q_{H H}^{*}=r_{H H}^{* *}-r_{H H}^{*}>0$ and $Q_{L L}^{* *}-Q_{L L}^{*}=r_{L L}^{* *}-r_{L L}^{*}>0$.

Proposition 4 indicates that the RPM induces the collector to obtain a higher collection quantity efficaciously. To reach the target collection quantity and avoid getting a penalty from the government, the manufacturer will increase the buy-back price to stimulate the collector under RPM, and then the collector increases the collection price to raise the collection quantity. From these comparisons, we obtain that the RPM is efficient in enhancing the collection of WEEE's quantity.

Proposition 5. Under the RPM, the manufacturer charges more franchise fees to ensure profit.

Proof. Combining equations (35) with equation (16), we have $T_{L}^{* *}-T_{L}^{*}=\left(b_{L}^{* *}-b_{L}^{*}\right)\left(b_{L}^{* *}+b_{L}^{*}+2 e_{L}\right) / 4>0$. Besides, by contrasting equation (36) with equation (17), we get $T_{H}^{*}{ }^{*}-T_{H}^{*}=a k\left(b_{H}^{* *}+b_{H}^{*}+2 e_{L}\right) /(2 \Delta+4 a)>0$.

From Propositions 4 and 5, we obtain that the manufacturer increases the buy-back price to stimulate the third- party collector to collect more WEEEs under the RPM. However, to obtain more profits, the manufacturer charges the collector more franchise fees.

\section{Numerical Examples}

5.1. Analysis of the CLSC without RPM. A numerical analysis is provided to illustrate the optimal decisions under Case 1. Based on data by examining several companies and combining with actual situations $[13,22]$, we let $c_{n}=60 c_{r}=45$, $a=4, \phi=120, e_{H}=10, e_{L}=7, \pi_{r}^{0}=200, \Delta=c_{n}-c_{r}=15$, $v \in(0.1,0.2,0.3,0.4,0.5,0.6,0.7,0.8,0.9)$. And Table 3 gives the optimal decisions of Case 1 with different $v$. By analyzing Table 3, we find the following.

As $v$ increases, the buy-back price $b_{H}^{*}$, collection price $r_{H H}^{*}$, and collection quantity $Q_{H H}^{*}$ are unchanged, while the buy-back price $b_{L}^{*}$, collection price $r_{L L}^{*}$, and collection quantity $Q_{L L}^{*}$ decrease. In equation (14), differentiating $b_{H}^{*}$ with respect to $v$, we obtain $\mathrm{d} b_{H}^{*} / \mathrm{d} v=0$. That illustrates the manufacturer offers $\mathrm{H}$-type collectors a fixed buy-back price whatever $v$ changes. Similarly, we have $\mathrm{d} b_{L}^{*} / \mathrm{d} v=-2 a\left(e_{H}-e_{L}\right) /(\Delta+2 a)(1-v)^{2}<0$. From equations (18) and (19), we obtain collection price and buy-back price having the same trend. Similarly, the collection quantity and the collection price have the same trend. Those trends are consistent with Table 3.

With $v$ increasing, the franchise fee $T_{H}^{*}$ increases, while $T_{L}^{*}$ decreases. In equation (16), we can get $\mathrm{d} T_{L}^{*} / \mathrm{d} v=\left[\left(b_{L}^{*}+e_{L}\right) / 2\right]\left(\mathrm{d} b_{L}^{*} / \mathrm{d} v\right)<0$, which implies that the manufacturer charges L-type collector lower franchise fee with a larger $v$. In equation (17), we get $\mathrm{d} T_{H}^{*} / \mathrm{d} v=\left[\left(b_{H}^{*}+\right.\right.$ $\left.\left.e_{H}\right) / 2\right]\left(\mathrm{d} b_{H}^{*} / \mathrm{d} v\right)-\left[\left(e_{H}-e_{L}\right) / 2\right]\left(\mathrm{d} b_{L}^{*} / \mathrm{d} v\right)$. Besides, we have $d b_{H}^{*} / d v=0, \mathrm{~d} T_{L}^{*} / \mathrm{d} v<0$, and $e_{H}>e_{L}$, and hence, we obtain $\mathrm{d} T_{H}^{*} / \mathrm{d} v>0$. That proves the manufacturer charges H-type collector more franchise fee with $v$ becoming larger. Therefore, the manufacturer ensures his profit by charging more franchise fees.

With $v$ increasing, the expected profit of manufacturer increases, whereas the expected profit of collector decreases when $\mathrm{H}$-type collector opts the $G_{H}$. When the L-type collector adopts $G_{L}$, the manufacturer's profit decreases with $v$ increasing, and the third-party collector gets the conserved profit. When the H-type collector chooses $G_{H}$, the manufacturer increases the franchise fee $T_{H}^{*}$ with $v$ increasing. That reduces the collector's profit but the H-type collector's profit is still larger than the conserved profit. Therefore, the H-type collector accepts the screening contract for more profits. When the L-type collector opts $G_{L}$, the franchise fee $T_{L}^{*}$ decreases with $v$ increasing. The L-type collector gets only the conserved profit. Therefore, the L-type collector also accepts the screening contract.

5.2. Analysis of the CLSC with RPM. To investigate the impact of the RPM, we adopt the same parameters as these in Section 5.1. Besides, we have $k \in(10,20,30,40), Q_{0}=25$. The numerical results of CLSC with RPM are shown in Figures 2-7. 
TABLE 3: The optimal decisions of Case 1 with different $v$.

\begin{tabular}{|c|c|c|c|c|c|c|c|c|c|}
\hline & & & & & $v$ & & & & \\
\hline & 0.1 & 0.2 & 0.3 & 0.4 & 0.5 & 0.6 & 0.7 & 0.8 & 0.9 \\
\hline$b_{H}^{*}$ & 33.913 & 33.913 & 33.913 & 33.913 & 33.913 & 33.913 & 33.913 & 33.913 & 33.913 \\
\hline$b_{L}^{*}$ & 35.754 & 35.609 & 35.422 & 35.174 & 34.826 & 34.304 & 33.435 & 31.696 & 26.478 \\
\hline$T_{H}^{*}$ & 203.457 & 203.675 & 203.954 & 204.327 & 204.849 & 205.631 & 206.936 & 209.544 & 217.370 \\
\hline$T_{L}^{*}$ & 244.718 & 241.626 & 237.665 & 232.410 & 225.106 & 214.263 & 196.493 & 162.089 & 67.949 \\
\hline$r_{H H}^{*}$ & 11.957 & 11.957 & 11.957 & 11.957 & 11.957 & 11.957 & 11.957 & 11.957 & 11.957 \\
\hline$r_{L L}^{*}$ & 14.377 & 14.304 & 14.211 & 14.087 & 13.913 & 13.652 & 13.217 & 12.348 & 9.739 \\
\hline$Q_{H H}^{*}$ & 21.957 & 21.957 & 21.957 & 21.957 & 21.957 & 21.957 & 21.957 & 21.957 & 21.957 \\
\hline$Q_{L L}^{*}$ & 21.377 & 21.304 & 21.211 & 21.087 & 20.913 & 20.652 & 20.217 & 19.348 & 16.739 \\
\hline$E\left(\pi_{m H}^{*}\right)$ & 697.500 & 697.717 & 697.997 & 698.370 & 698.891 & 699.674 & 700.978 & 703.587 & 711.413 \\
\hline$E\left(\pi_{m L}^{*}\right)$ & 698.784 & 698.745 & 698.650 & 698.446 & 698.011 & 697.033 & 694.533 & 686.272 & 635.402 \\
\hline$E\left(\pi_{r H H}^{*}\right)$ & 253.630 & 253.413 & 253.134 & 252.761 & 252.239 & 251.457 & 250.152 & 247.544 & 239.717 \\
\hline$E\left(\pi_{r L L}^{*}\right)$ & 200.000 & 200.000 & 200.000 & 200.000 & 200.000 & 200.000 & 200.000 & 200.000 & 200.000 \\
\hline
\end{tabular}
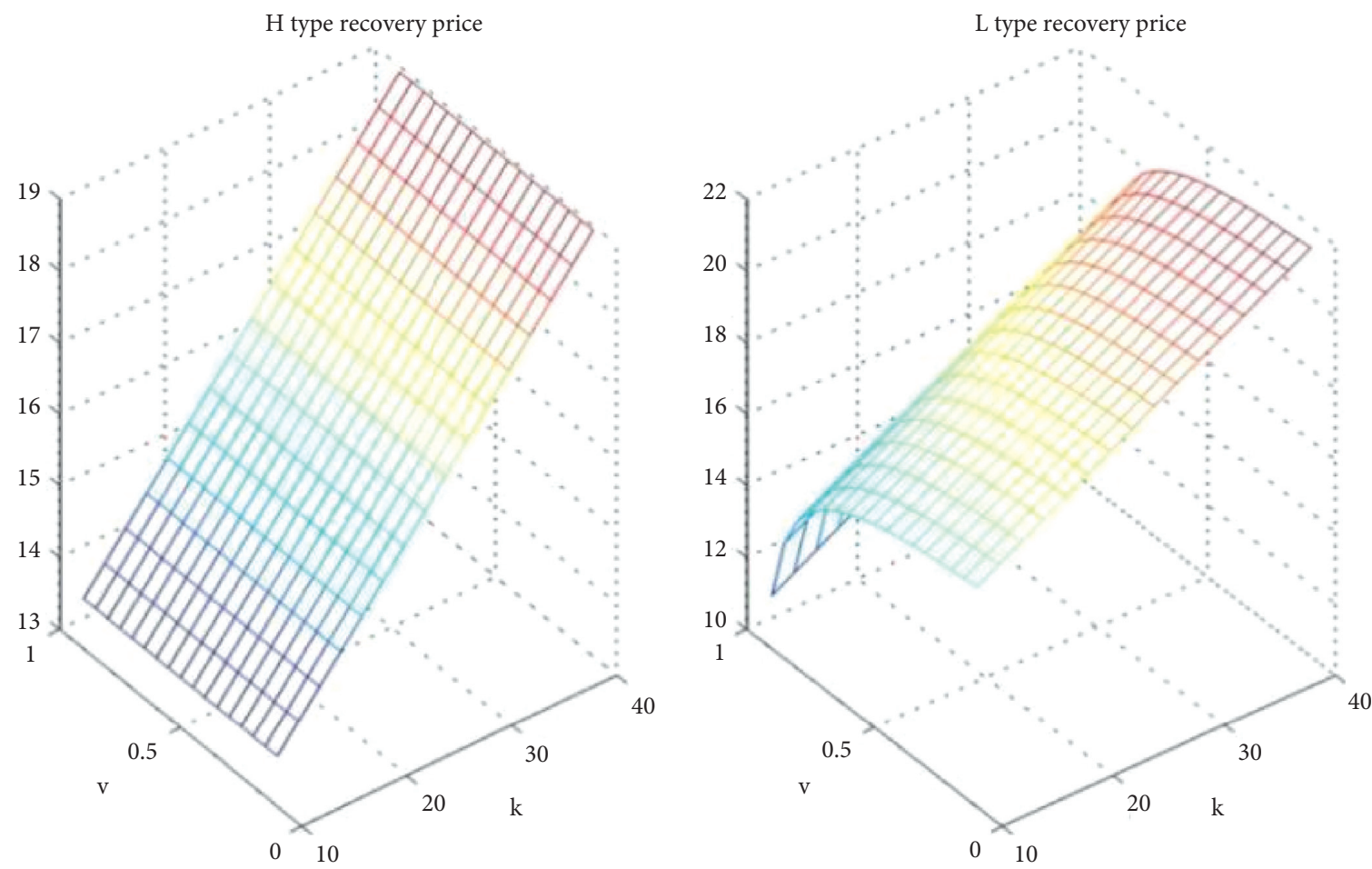

FIGURE 2: The changing trend of buy-back price $b_{H}^{* *}$ (a) and $b_{L}^{* *}$ (b).

As shown in Figures 2-4, the buy-back price, collection price, and collection quantity are increasing with the rewardpenalty intensity $k$ getting larger. In equation (33), we obtain $\mathrm{d} b_{H}^{* *} / \mathrm{d} k=2 a /(\Delta+2 a)>0$. And in equation (34), we have $\partial b_{L}^{* *} / \partial k=2 a /(\Delta+2 a)>0$. Besides, differentiating $r_{H H}^{*}$ on $k$, we obtain $\mathrm{d} r_{H H}^{* *} / \mathrm{d} k=a /(\Delta+2 a)>0$. And taking derivative of $r_{L L}^{*}$ about $k$, we have $\mathrm{d} r_{L L}^{* *} / \mathrm{d} k=a /(\Delta+2 a)>0$. Besides, we have $d Q_{H H}^{*} / d k=a /(\Delta+2 a)>0$ and $\partial Q_{L L}^{* *} / \partial k=a /(\Delta+2 a)>0, \quad$ respectively. Besides, from Proposition 4, we get $b_{H}^{* *}>b_{H}^{*} b_{L}^{* *}>b_{L}^{*} r_{H H}^{* *}>r_{H H}^{*} r_{L L}^{*}>r_{L L}^{*}$, $Q_{H H}^{* *}>Q_{H H}^{*}$, and $Q_{L L}^{*}>Q_{L L}^{*}$. The results show that the buyback price, collection price, and collection quantity are enhanced under the RPM. The government guides the process of collection effectively in CLSC.
As shown in Figure 5, the franchise fee $T_{H}^{* *}$ and $T_{L}^{* *}$ is enhanced with the increasing reward-penalty intensity. In equations (35) and (36), we have $\mathrm{d} T_{L}^{* *} / \mathrm{d} k=$ $a\left(b_{L}^{* *}+e_{L}\right) /(\Delta+2 a)>0 \quad$ and $\quad d T_{H}^{* *} / d k=a\left(b_{H}^{* *}+e_{L}\right)$ $/(\Delta+2 a)>0$. Besides, from Proposition $5, T_{H}^{* *}>T_{H}^{*}$ and $T_{L}^{* *}>T_{L}^{*}$ can be clearly obtained. Therefore, the manufacturer enhances franchise fees to achieve more profits when increasing reward-penalty intensity.

In Figure 6, the expected profits of the manufacturer $E\left(\pi_{m H}^{* *}\right)$ and $E\left(\pi_{m L}^{* *}\right)$ are increasing initially and then are decreasing with increasing reward-penalty intensity. Figure 7 shows that the expected profit of the collector $E\left(\pi_{r H H}^{* *}\right)$ increases with increasing reward-penalty intensity, while the expected profit $E\left(\pi_{r L L}^{* *}\right)$ is the conserved profit. Furthermore, 

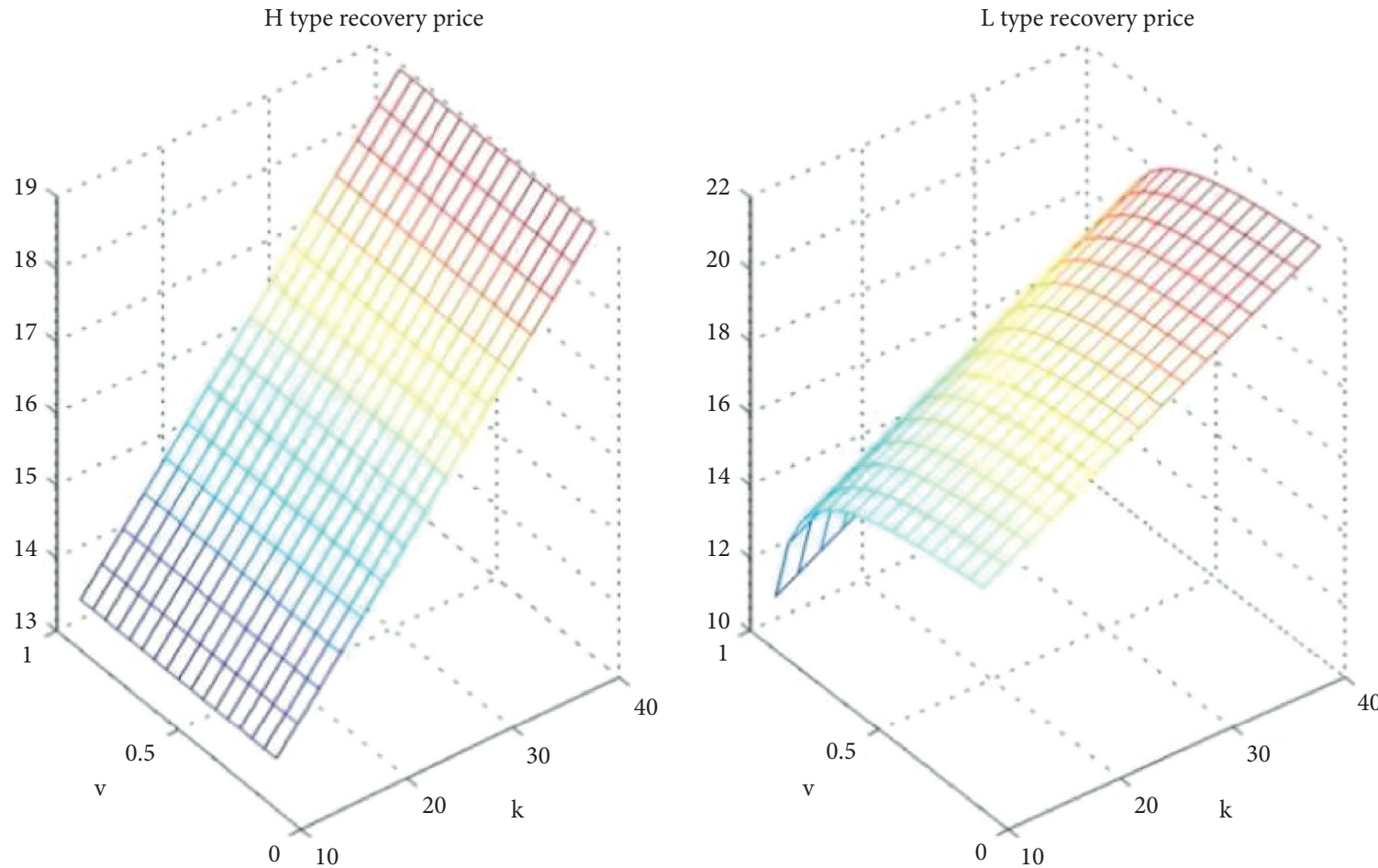

FIGURE 3: The changing trend of collection price $r_{H H}^{* *}$ (a) and $r_{L L}^{* *}(\mathrm{~b})$.
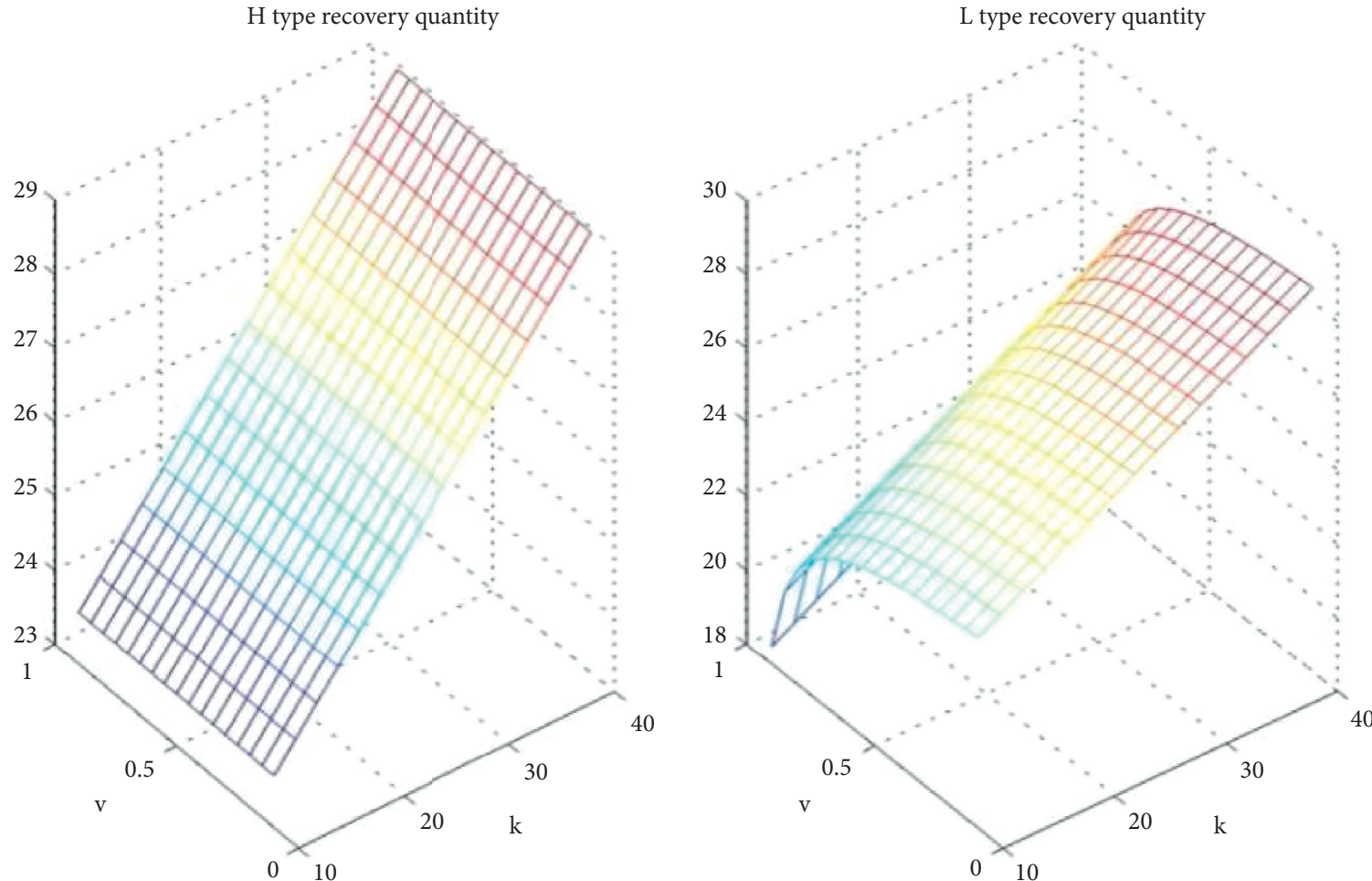

Figure 4: The changing trend of collection quantity $Q_{H H}^{* *}$ (a) and $Q_{L L}^{* *}(\mathrm{~b})$.

we find that the expected profits of the manufacturer are decreasing when the reward-penalty intensity increases from 10 to 20 . The collection quantity exceeds the targeted collection quantity at the beginning, and then, it gradually rises when the reward-penalty intensity increases from 20 to 40 . Under RPM, the H-type collector enhances the buy-back price and his expected profit grows with the increase of reward-penalty intensity. The L-type collector obtains only 

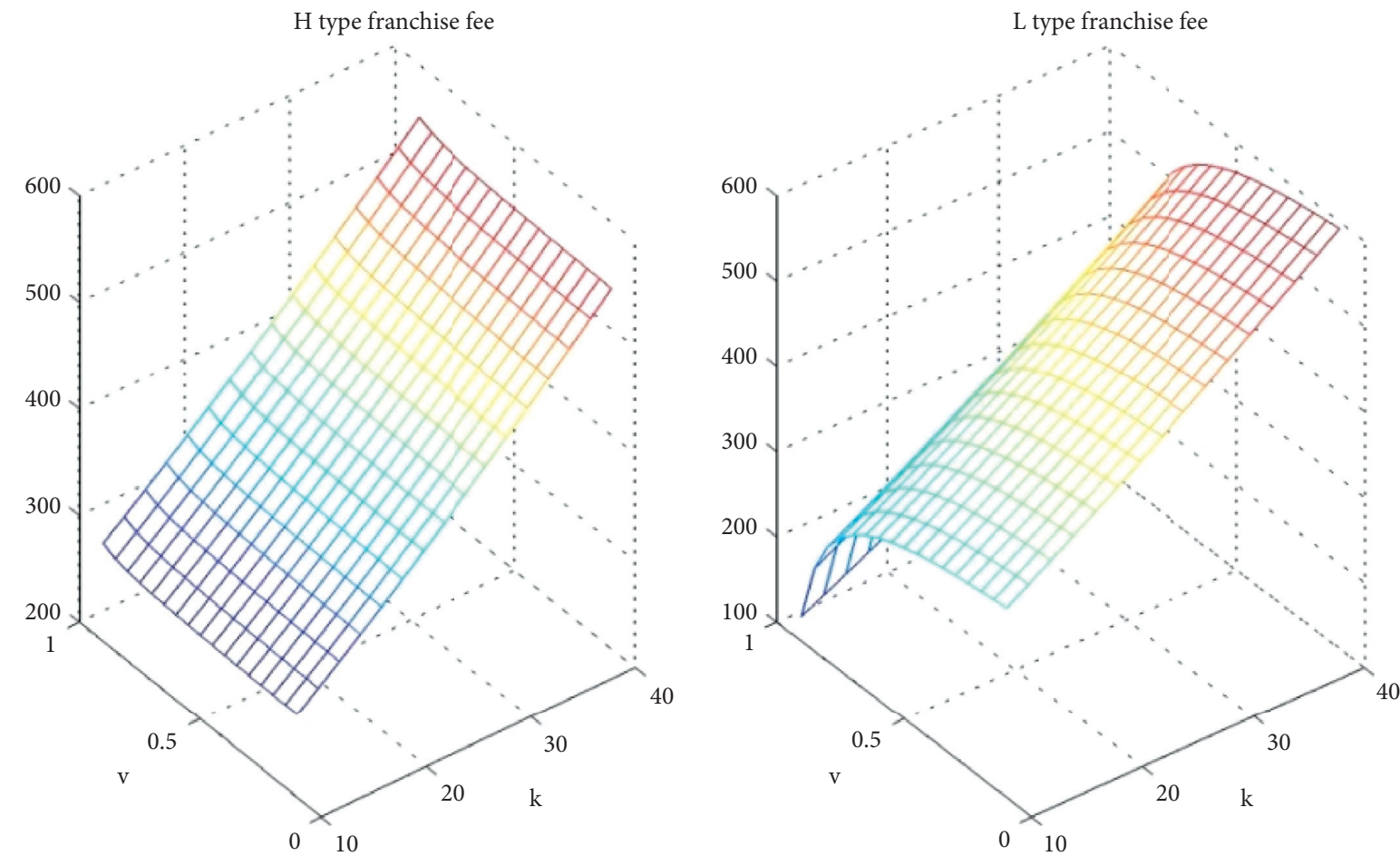

FIgURE 5: The changing trend of franchise fees $T_{H}^{* *}$ (a) and $T_{L}^{* *}$ (b).
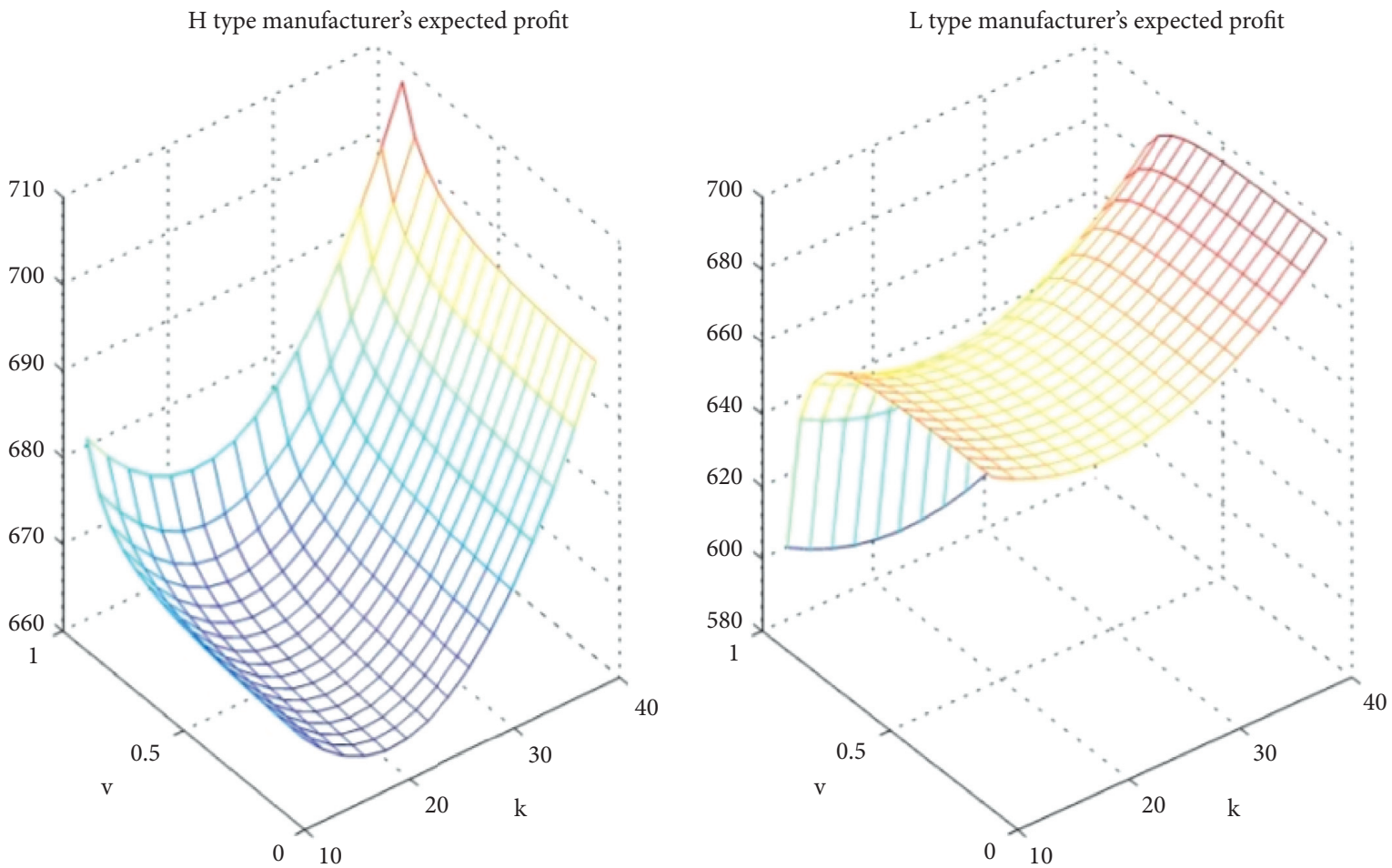

Figure 6: The changing trend of manufacturer's expected profit $E\left(\pi_{m H}^{* *}\right)$ (a) and $E\left(\pi_{m L}^{* *}\right)(\mathrm{b})$.

the conserved profits. Besides, we find $E\left(\pi_{m H}^{* *}\right)<E\left(\pi_{m H}^{*}\right)$ and $E\left(\pi_{m L}^{* *}\right)<E\left(\pi_{m L}^{*}\right)$, which indicate that the expected profit of manufacturer under RPM is lower than the case without RPM. When $k=40$, the expected profit of the manufacturer under RPM is extremely close to that without RPM. But the profit of the collector under RPM is larger than the case without RPM, which means the collector is stimulated by RPM and has a positive attitude for collecting 

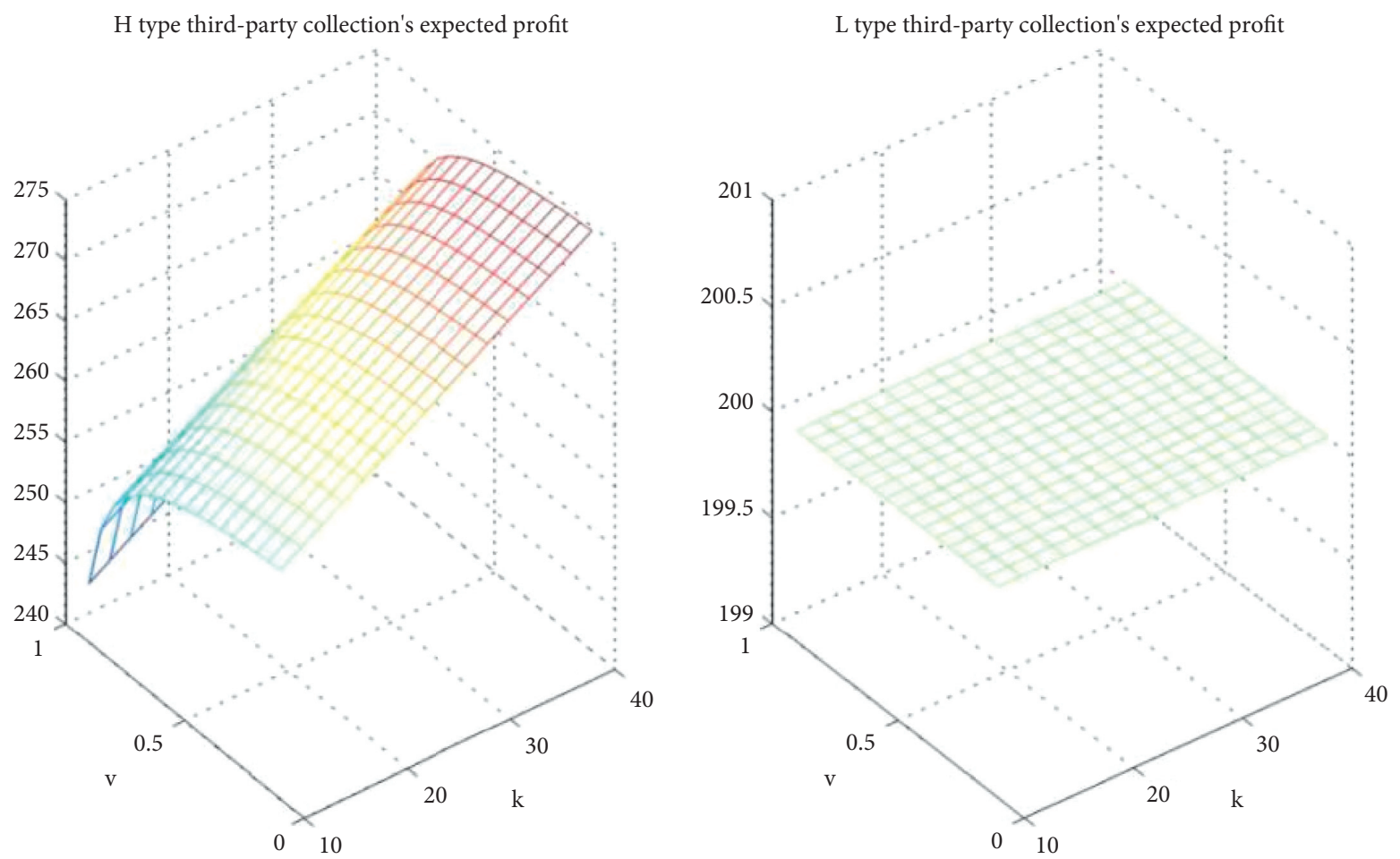

FIGURE 7: The changing trend of collector's expected profit $E\left(\pi_{r H H}^{* *}\right)(\mathrm{a})$ and $E\left(\pi_{r L L}^{* *}\right)(\mathrm{b})$.

WEEEs. If the reward-penalty intensity keeps increasing, the expected profit of the manufacturer will outstrip his expected profit under the case without RPM. It explains that the manufacturer gets more expected profit with the increase of reward-penalty intensity.

\section{Conclusions, Managerial Implications, and Future Research}

This paper explores the reward-penalty mechanism (RPM) in a closed-loop supply chain (CLSC), where the manufacturer delegates the WEEE collection to a third-party collector, who has the private information of the collection effort level. We provide an information screening contract for the manufacturer to capture the private information of the collector. The optimal decision-making results, with principal-agent theory, are obtained by solving the models. The conclusions and managerial implications are as follows:

(i) The information screening contract makes it feasible that the manufacturer obtains third-party collector's collection effort level with and without RPM. Therefore, for manufacturers, we recommend that they should adopt an information screening contract to obtain other corporations' private information. In addition, they increase the buy-back price to stimulate the third-party collector to collect waste products under RPM and to avoid punishment by the government.

(ii) The RPM has a significant impact on the performance of CLSC with asymmetric information. The profits of the collector with RPM are larger than those without RPM. And the collection quantity is enhanced by implementing RPM. For government managers, we suggest that they provide RPM to improve the efficiency of enterprises for raising the collection quantity and bringing more environmental benefits.

(iii) H-type collector collects more WEEEs and earns more profits than L-type collector. With the information screening contract, the $\mathrm{H}$-type collector chooses the contract $G_{H}$ and the L-type collector chooses the contract $G_{L}$. Therefore, for third-party collectors, we propose that they cooperate with the manufacturer actively. Although the manufacturer charges more franchise fees, they also increase the buy-back price, and the profits of collectors become larger than the case without RPM. Furthermore, regardless of RPM, collectors should ensure that the collection effort level is H-type for obtaining more profits. Simultaneously, when cooperating with the manufacturer, collectors should truthfully deliver the right private information for obtaining more profits. This conclusion complements the research on asymmetric information of third-party collectors in Wang et al. [15].

6.1. Future Research. In this paper, we assume that enterprises are risk neutral, but in practice, enterprises have risk preference or risk averse. Therefore, the one of research directions is that the impact of the government's RPM on CLSC with asymmetric information when enterprises have different risk preferences, such as risk averse and risk loving. 
Moreover, we only suppose that the third-party collector has private information. In most cases, every enterprise in a supply chain has private information. Therefore, another research direction is that the other CLSC members also have private information besides third-party collectors.

\section{Appendix}

\section{A. The process of solving Case 1}

Assume $Z_{H}=e_{H}+r_{H H}-\phi+p Z_{L}=e_{L}+r_{L L}-\phi+p$; we then have

$$
\begin{aligned}
& E\left(\pi_{m H}\right)= \int_{0}^{Z_{H}}(\phi-p+x)\left(p-c_{r}\right) f(x) \mathrm{d} x+\int_{Z_{H}}^{a}\left(\phi-p+x-e_{H}-r_{H H}\right)\left(p-c_{n}\right) f(x) \mathrm{d} x \\
&+\int_{Z_{H}}^{a}\left(e_{H}+r_{H H}\right)\left(p-c_{r}\right) f(x) d x-b_{H}\left(e_{H}+r_{H H}\right)+T_{H}, \\
& E\left(\pi_{m L}\right)= \int_{0}^{Z_{L}}(\phi-p+x)\left(p-c_{r}\right) f(x) \mathrm{d} x+\int_{Z_{L}}^{a}\left(\phi-p+x-e_{L}-r_{L L}\right)\left(p-c_{n}\right) f(x) d x \\
&+\int_{Z_{L}}^{a}\left(e_{L}+r_{L L}\right)\left(p-c_{r}\right) f(x) \mathrm{d} x-b_{L}\left(e_{L}+r_{L L}\right)+T_{L}, \\
& E\left(\pi_{r H H}\right)=\left(b_{H}-r_{H H}\right)\left(e_{H}+r_{H H}\right)-\frac{e_{H}^{2}}{4}-T_{H}, \\
& E\left(\pi_{r H L}\right)=\left(b_{L}-r_{H L}\right)\left(e_{H}+r_{H L}\right)-\frac{e_{H}^{2}}{4}-T_{L}, \\
& E\left(\pi_{r L L}\right)=\left(b_{L}-r_{L L}\right)\left(e_{L}+r_{L L}\right)-\frac{e_{L}^{2}}{4}-T_{L}, \\
& E\left(\pi_{r L H}\right)=\left(b_{H}-r_{L H}\right)\left(e_{L}+r_{L H}\right)-\frac{e_{L}^{2}}{4}-T_{H}, \\
& \max E\left(\pi_{m}\right)= v E\left(\pi_{m H}\right)+(1-v) E\left(\pi_{m L}\right), \\
& E\left(\pi_{r H H}\right) \geq \pi_{r}^{0}, \\
& r_{H H}^{*}= \arg \max E\left(\pi_{r H H}\right), \\
& r_{L L}^{*}= \arg \max E\left(\pi_{r H H}\right) \geq \\
& E\left(\pi_{r L L}\right), \\
& E\left(\pi_{r L L}\right) \geq E\left(\pi_{r L H}\right), \\
& \pi_{r}^{0},
\end{aligned}
$$


According to equations (A.8) and (A.9), $r_{H H}^{*}$ and $r_{L L}^{*}$ are solved out. Then, taking derivative of $r_{H H}^{*}$ and $r_{L L}^{*}$ in the light of limit derivation rule, the following two formulas are obtained by $\partial E\left(\pi_{r H H}\right) / \partial r_{H H}=0$ and $\partial E\left(\pi_{r L L}\right) / \partial r_{L L}=0$ :

$$
\begin{gathered}
\frac{\partial E\left(\pi_{r H H}\right)}{\partial r_{H H}}=-\left(e_{H}+r_{H H}\right)+\left(b_{H}-r_{H H}\right)=b_{H}-e_{H}-2 r_{H H}=0, \\
\frac{\partial E\left(\pi_{r L L}\right)}{\partial r_{L L}}=-\left(e_{L}+r_{L L}\right)+\left(b_{L}-r_{L L}\right)=b_{L}-e_{L}-2 r_{L L}=0 .
\end{gathered}
$$

Because $\partial^{2} E\left(\pi_{r H H}\right) / \partial r_{H H}^{2}<0$ and $\partial^{2} E\left(\pi_{r L L}\right) / \partial r_{L L}^{2}<0$, equations (A.3) and (A.5) have the maximum values, respectively. By solving equations (A.14) and (A.15), we obtain the optimal values of $r_{H H}^{*}$ and $r_{L L}^{*}$.

$$
\begin{gathered}
r_{H H}^{*}=\frac{b_{H}^{*}-e_{H}}{2}, \\
r_{L L}^{*}=\frac{b_{L}^{*}-e_{L}}{2} .
\end{gathered}
$$

To obtain the optimal results of the model, we need to solve out $r_{H L}^{*}$ and $r_{L H}^{*}$. In terms of the limit derivation rule, we get the partial derivative and make it equal 0 . The formulas are as follows:

$$
\begin{aligned}
& \frac{\partial E\left(\pi_{r H L}\right)}{\partial r_{H L}}=-\left(e_{H}+r_{H L}\right)+\left(b_{L}-r_{H L}\right)=b_{L}-e_{H}-2 r_{H L}=0, \\
& \frac{\partial E\left(\pi_{r L H}\right)}{\partial r_{L H}}=-\left(e_{L}+r_{L H}\right)+\left(b_{H}-r_{L H}\right)=b_{H}-e_{L}-2 r_{L H}=0 .
\end{aligned}
$$

Because $\partial^{2} E\left(\pi_{r H L}\right) / \partial r_{H L}^{2}<0$ and $\partial^{2} E\left(\pi_{r L H}\right) / \partial r_{L H}^{2}<0$, equations (A.3) and (A.5) are convex, respectively. By solving equations (A.18) and (A.19), we get

$$
\begin{aligned}
& r_{H L}^{*}=\frac{b_{L}^{*}-e_{H}}{2}, \\
& r_{L H}^{*}=\frac{b_{H}^{*}-e_{L}}{2} .
\end{aligned}
$$

$$
\begin{aligned}
E\left(\pi_{m H}\right)= & \int_{0}^{Z_{H}}(\phi-p+x)\left(p-c_{r}\right) f(x) \mathrm{d} x+\int_{Z_{H}}^{a}\left(\phi-p+x-\frac{b_{H}+e_{H}}{2}\right)\left(p-c_{n}\right) f(x) \mathrm{d} x \\
& +\int_{Z_{H}}^{a}\left(\frac{b_{H}+e_{H}}{2}\right)\left(p-c_{r}\right) f(x) \mathrm{d} x-b_{H}\left(\frac{b_{H}+e_{H}}{2}\right)+T_{H}, \\
E\left(\pi_{m L}\right)= & \int_{0}^{Z_{L}}(\phi-p+x)\left(p-c_{r}\right) f(x) d x+\int_{Z_{L}}^{a}\left(\phi-p+x-\frac{b_{L}+e_{L}}{2}\right)\left(p-c_{n}\right) f(x) \mathrm{d} x \\
& +\int_{Z_{L}}^{a}\left(\frac{b_{L}+e_{L}}{2}\right)\left(p-c_{r}\right) f(x) \mathrm{d} x-b_{L}\left(\frac{b_{L}+e_{L}}{2}\right)+T_{L}, \\
E\left(\pi_{r H H}\right)= & \left(\frac{b_{H}+e_{H}}{2}\right)^{2}-\frac{e_{H}^{2}}{4}-T_{H},
\end{aligned}
$$




$$
\begin{aligned}
& E\left(\pi_{r H L}\right)=\left(\frac{b_{L}+e_{H}}{2}\right)^{2}-\frac{e_{H}^{2}}{4}-T_{L}, \\
& E\left(\pi_{r L L}\right)=\left(\frac{b_{L}+e_{L}}{2}\right)^{2}-\frac{e_{L}^{2}}{4}-T_{L}, \\
& E\left(\pi_{r L H}\right)=\left(\frac{b_{H}+e_{L}}{2}\right)^{2}-\frac{e_{L}^{2}}{4}-T_{H} .
\end{aligned}
$$

Considering $b_{L}\left(e_{H}-e_{L}\right) / 2>0$ and $E\left(\pi_{r L L}\right) \geq \pi_{r}^{0}$, we get $E\left(\pi_{r H H}\right) \geq E\left(\pi_{r H L}\right)=E\left(\pi_{r L L}\right)+\left(b_{L}\left(e_{H}-e_{L}\right) / 2\right) \geq \pi_{r}^{0}$. The constraint $E\left(\pi_{r H H}\right) \geq \pi_{r}^{0}$ can be ignored.
The relative Lagrange multiplier of equations (A.10), (A.12), and (A.13) are denoted by $\lambda, \mu$, and $\gamma$, respectively. So we get

$L\left(b_{H}, b_{L}, T_{H}, T_{L}, \lambda, \mu, \gamma\right)=v E\left(\pi_{m H}\right)+(1-v) E\left(\pi_{m L}\right)+\lambda\left(E\left(\pi_{r L L}\right)-\pi_{r}^{0}\right)+\mu\left(E\left(\pi_{r H H}\right)-E\left(\pi_{r H L}\right)\right)+\gamma\left(E\left(\pi_{r L L}\right)-E\left(\pi_{r L H}\right)\right)$.

Taking partial derivative of equation (A.28), we obtain the optimal $K-T$ condition:

$$
\begin{aligned}
\frac{\partial L}{\partial b_{H}}= & v\left[-\frac{1}{2} \int_{Z_{H}}^{a}\left(p-c_{n}\right) f(x) \mathrm{d} x+\frac{1}{2} \int_{Z_{H}}^{a}\left(p-c_{r}\right) f(x) \mathrm{d} x-\left(\frac{2 b_{H}+e_{H}}{2}\right)\right]+\mu\left(\frac{b_{H}+e_{H}}{2}\right)-\gamma\left(\frac{b_{H}+e_{L}}{2}\right)=0 \\
\frac{\partial L}{\partial b_{L}}= & (1-v)\left[-\frac{1}{2} \int_{Z_{L}}^{a}\left(p-c_{n}\right) f(x) \mathrm{d} x+\frac{1}{2} \int_{Z_{L}}^{a}\left(p-c_{r}\right) f(x) \mathrm{d} x-\left(\frac{2 b_{L}+e_{L}}{2}\right)\right] \\
& +\lambda\left(\frac{b_{L}+e_{L}}{2}\right)-\mu\left(\frac{b_{L}+e_{H}}{2}\right)+\gamma\left(\frac{b_{L}+e_{L}}{2}\right)=0 \\
\frac{\partial L}{\partial T_{H}}= & v-\mu+\gamma=0 \\
\frac{\partial L}{\partial T_{L}}= & (1-v)-\lambda+\mu-\gamma=0 .
\end{aligned}
$$

Solving the optimal conditions of $K-T$, we get $\lambda=1$ and $\mu=v+\gamma$. We get $\lambda>0$ and $\mu>0$. Further, we acquire $\gamma=0$.

(Disproof: Assume $\gamma>0$, according to $K-T$ conditions; the correspondent inequality equation (A.13) must be equality. Similarly, $\mu>0$ means constraint equation (A.12) is equality. So, we have $b_{H}=b_{L}$ and $T_{H}=T_{L}$ from the two constraints equations (A.12) and (A.13). In such setting, the third-party collector faces the same contracts when he chooses $H$ contract or $L$ contract; thus, the contracts are mixed up. However, the collectors who choose different contracts are intermingled and harm the interests of enterprises under the mixed-up contracts. So, the assumption $\gamma>0$ is not supported and then we obtain $\gamma=0$.)

Taking $\lambda=1, \mu=v$, and $\gamma=0$ into the optimal conditions of $K-T$, we obtain 


$$
\begin{aligned}
\frac{\partial L}{\partial b_{H}}= & v\left[-\frac{1}{2}\left(p-c_{n}\right) \int_{Z_{H}}^{a} f(x) \mathrm{d} x+\left(p-c_{r}\right) \frac{1}{2} \int_{Z_{H}}^{a} f(x) \mathrm{d} x-\frac{b_{H}}{2}\right]=0, \\
\frac{\partial L}{\partial b_{L}}= & -\frac{1}{2}\left(p-c_{n}\right) \int_{Z_{L}}^{a} f(x) \mathrm{d} x+\left(p-c_{r}\right) \frac{1}{2} \int_{Z_{L}}^{a} f(x) \mathrm{d} x-\frac{b_{L}}{2} \\
& -v\left[-\frac{1}{2}\left(p-c_{n}\right) \int_{Z_{L}}^{a} f(x) \mathrm{d} x+\left(p-c_{r}\right) \frac{1}{2} \int_{Z_{L}}^{a} f(x) \mathrm{d} x-\frac{b_{L}}{2}+\frac{e_{H}-e_{L}}{2}\right]=0,
\end{aligned}
$$

Taking function $f(x)=\left\{\begin{array}{ll}1 / a, & x \in(0, a), \\ 0, & \text { others, }\end{array}, Z_{H}=e_{H}+\right.$ $r_{H H}-\phi+p$, and $Z_{L}=e_{L}+r_{L L}-\phi+p$ into equations (A.33) and (A.34), and solving out equations (A.35) and (A.36), we can derive the optimal buy-back price of different types, respectively.

$$
\begin{aligned}
& b_{H}^{*}=\frac{\Delta\left(2 a-e_{H}+2 \phi-2 p\right)}{\Delta+2 a}, \\
& b_{L}^{*}=\frac{\Delta\left(2 a-e_{L}+2 \phi-2 p\right)-2 a e_{L}}{\Delta+2 a}+\frac{2 a\left(e_{L}-v e_{H}\right)}{(1-v)(\Delta+2 a)} .
\end{aligned}
$$

$\lambda=1>0$, we let $E\left(\pi_{r L L}\right)=\left(b_{L}-r_{L L}\right)\left(e_{L}+r_{L L}\right)-e_{L}^{2} / 4-$ $T_{L}=\left(\left(b_{L}+e_{L}\right) / 2\right)^{2}-\left(e_{L}^{2} / 4\right)-T_{L}=0$, and then we get

$$
T_{L}^{*}=\frac{\left(b_{L}^{*}+e_{L}\right)^{2}-e_{L}^{2}}{4}-\pi_{r}^{0}
$$

Similarly, we let $E\left(\pi_{r H H}\right)=\left(b_{H}-r_{H H}\right)\left(e_{H}+r_{H H}\right)$ $-\left(e_{H}^{2} / 4\right)-T_{H}=\left(b_{L}-r_{H L}\right)\left(e_{H}+r_{H L}\right)-\left(e_{H}^{2} / 4\right)-\quad T_{L}=E$ $\left(\pi_{r H L}\right)$, and then we get

$$
T_{H}^{*}=\frac{\left(b_{H}^{*}+e_{H}\right)^{2}-\left(b_{L}^{*}+e_{H}\right)^{2}}{4}+T_{L}^{*} .
$$

The process of solving Case 2 .

Proof

$$
\begin{aligned}
E\left(\pi_{m H}\right)= & \int_{0}^{Z_{H}}(\phi-p+x)\left(p-c_{r}\right) f(x) d x+\int_{Z_{H}}^{a}\left(\phi-p+x-e_{H}-r_{H H}\right)\left(p-c_{n}\right) f(x) d x \\
& +\int_{Z_{H}}^{a}\left(e_{H}+r_{H H}\right)\left(p-c_{r}\right) f(x) d x-b_{H}\left(e_{H}+r_{H H}\right)+T_{H}+k\left(e_{H}+r_{H H}-Q_{0}\right), \\
E\left(\pi_{m L}\right)= & \int_{0}^{Z_{L}}(\phi-p+x)\left(p-c_{r}\right) f(x) d x+\int_{Z_{L}}^{a}\left(\phi-p+x-e_{L}-r_{L L}\right)\left(p-c_{n}\right) f(x) d x \\
& +\int_{Z_{L}}^{a}\left(e_{L}+r_{L L}\right)\left(p-c_{r}\right) f(x) d x-b_{L}\left(e_{L}+r_{L L}\right)+T_{L}+k\left(e_{L}+r_{L L}-Q_{0}\right), \\
E\left(\pi_{r H H}\right)= & \left(b_{H}-r_{H H}\right)\left(e_{H}+r_{H H}\right)-\frac{e_{H}^{2}}{4}-T_{H}, \\
E\left(\pi_{r H L}\right)= & \left(b_{L}-r_{H L}\right)\left(e_{H}+r_{H L}\right)-\frac{e_{H}^{2}}{4}-T_{L}, \\
E\left(\pi_{r L L}\right)= & \left(b_{L}-r_{L L}\right)\left(e_{L}+r_{L L}\right)-\frac{e_{L}^{2}}{4}-T_{L}, \\
\max E\left(\pi_{m}\right)= & v E\left(\pi_{m H}\right)+(1-v) E\left(\pi_{m L}\right), \\
r_{H H}^{* *}= & \arg \max E\left(\pi_{r H H}\right), \\
r_{L L}^{* *}= & \arg \max E\left(\pi_{r L L}\right), \\
\left.r_{r L H}\right)= & \left(b_{H}-r_{L H}\right)\left(e_{L}+r_{L H}\right)-\frac{e_{L}^{2}}{4}-T_{H}, \\
&
\end{aligned}
$$




$$
\begin{aligned}
& E\left(\pi_{r H H}\right) \geq \pi_{r}^{0}, \\
& E\left(\pi_{r H H}\right) \geq E\left(\pi_{r H L}\right), \\
& E\left(\pi_{r L L}\right) \geq E\left(\pi_{r L H}\right),
\end{aligned}
$$

where $Z_{H}=e_{H}+r_{H H}-\phi+p$ and $Z_{L}=e_{L}+r_{L L}-\phi+p$.

According to (A.46) and (A.47), we obtain $r_{H H}^{* *}$ and $r_{L L}^{* *}$. Then, taking derivative of $r_{H H}^{* *}$ and $r_{L L}^{* *}$ in the light of limit derivation rule, the following two formulas can be obtained by $\partial E\left(\pi_{r H H}\right) / \partial r_{H H}=-\left(e_{H}+r_{H H}\right)+\left(b_{H}-r_{H H}\right)=b_{H}-$ $e_{H}-2 r_{H H}=0$ and $\partial E\left(\pi_{r L L}\right) / \partial r_{L L}=-\left(e_{L}+r_{L L}\right)+\left(b_{L}-\right.$ $\left.r_{L L}\right)=b_{L}-e_{L}-2 r_{L L}=0$.

Because $\partial^{2} E\left(\pi_{r H H}\right) / \partial r_{H H}^{2}<0$ and $\partial^{2} E\left(\pi_{r L L}\right) / \partial r_{L L}^{2}<0$, then from above equations, we obtain equations (A.52) and (A.53):

$$
\begin{gathered}
r_{H H}^{* *}=\frac{b_{H}^{* *}-e_{H}}{2} . \\
r_{L L}^{* *}=\frac{b_{L}^{* *}-e_{L}}{2} .
\end{gathered}
$$

To obtain the optimal results of the model, we need to solve out $r_{H L}^{* *}$ and $r_{L H}^{* *}$. In terms of the limit derivation rule, we get the partial derivative and make it equal $0 . \partial E$ $\left(\pi_{r H L}\right) / \partial r_{H L}=-\left(e_{H}+r_{H L}\right)+\left(b_{L}-r_{H L}\right)=b_{L}-e_{H}-2 r_{H L}$ $=0$ and $\partial E\left(\pi_{r L H}\right) / \partial r_{L H}=-\left(e_{L}+r_{L H}\right)+\left(b_{H}-r_{L H}\right)$ $=b_{H}-e_{L}-2 r_{L H}=0$.

Because $\partial^{2} E\left(\pi_{r H L}\right) / \partial r_{H L}^{2}<0$ and $\partial^{2} E\left(\pi_{r L H}\right) / \partial r_{L H}^{2}<0$, then by solving equations (A.14) and (A.15), from above equations, we solve out (A.54) and (A.55):

$$
\begin{aligned}
& r_{H L}^{* *}=\frac{b_{L}^{* *}-e_{H}}{2}, \\
& r_{L H}^{* *}=\frac{b_{H}^{* *}-e_{L}}{2} .
\end{aligned}
$$

To obtain the optimal results of the model, we take $r_{H H}^{* *}$, $r_{L L}^{* *}, r_{H L}^{* *}$, and $r_{L H}^{* *}$ into equations (A.39)-(A.44) and acquire the following:

$$
\begin{aligned}
E\left(\pi_{m H}\right)= & \int_{0}^{Z_{H}}(\phi-p+x)\left(p-c_{r}\right) f(x) \mathrm{d} x+\int_{Z_{H}}^{a}\left(\phi-p+x-\frac{b_{H}+e_{H}}{2}\right)\left(p-c_{n}\right) f(x) \mathrm{d} x \\
& +\int_{Z_{H}}^{a}\left(\frac{b_{H}+e_{H}}{2}\right)\left(p-c_{r}\right) f(x) \mathrm{d} x-b_{H}\left(\frac{b_{H}+e_{H}}{2}\right)+T_{H}+k\left(\frac{b_{H}+e_{H}}{2}-Q_{0}\right), \\
E\left(\pi_{m L}\right)= & \int_{0}^{Z_{L}}(\phi-p+x)\left(p-c_{r}\right) f(x) \mathrm{d} x+\int_{Z_{L}}^{a}\left(\phi-p+x-\frac{b_{L}+e_{L}}{2}\right)\left(p-c_{n}\right) f(x) \mathrm{d} x \\
& +\int_{Z_{L}}^{a}\left(\frac{b_{L}+e_{L}}{2}\right)\left(p-c_{r}\right) f(x) \mathrm{d} x-b_{L}\left(\frac{b_{L}+e_{L}}{2}\right)+T_{L}+k\left(\frac{b_{L}+e_{L}}{2}-Q_{0}\right), \\
E\left(\pi_{r H H}\right)= & \left(\frac{b_{H}+e_{H}}{2}\right)^{2}-\frac{e_{H}^{2}}{4}-T_{H}, \\
E\left(\pi_{r H L}\right)= & \left(\frac{b_{L}+e_{H}}{2}\right)^{2}-\frac{e_{H}^{2}}{4}-T_{L}, \\
E\left(\pi_{r L H}\right)= & \left(\frac{b_{H}+e_{L}}{2}\right)^{2}-\frac{e_{L}^{2}}{4}-T_{H} . \\
E\left(\pi_{r L L}\right)= & \left(\frac{b_{L}+e_{L}}{2}\right)^{2}-\frac{e_{L}^{2}}{4}-T_{L},
\end{aligned}
$$


In the original model, equation (A.49) can be ignored because $\quad E\left(\pi_{r H H}\right) \geq E\left(\pi_{r H L}\right)=E\left(\pi_{r L L}\right)+\left(\left(b_{L}\left(e_{H^{-}}\right.\right.\right.$ $\left.\left.\left.e_{L}\right)\right) / 2\right) \geq \pi_{r}^{0}$.
The relative Lagrange multiplier of equations (A.48), (A.50), and (A.51) are denoted by $\lambda, \mu$, and $\gamma$. So we obtain

$$
L\left(b_{H}, b_{L}, T_{H}, T_{L}, \lambda, \mu, \gamma\right)=v E\left(\pi_{m H}\right)+(1-v) E\left(\pi_{m L}\right)+\lambda\left(E\left(\pi_{r L L}\right)-\pi_{r}^{0}\right)+\mu\left(E\left(\pi_{r H H}\right)-E\left(\pi_{r H L}\right)\right)+\gamma\left(E\left(\pi_{r L L}\right)-E\left(\pi_{r L H}\right)\right)
$$

Taking partial derivative of equation (A.62) obtains the following optimal conditions of $K-T$ :

$$
\begin{aligned}
\frac{\partial L}{\partial b_{H}} & =v\left[-\frac{1}{2} \int_{Z_{H}}^{a}\left(p-c_{n}\right) f(x) \mathrm{d} x+\frac{1}{2} \int_{Z_{H}}^{a}\left(p-c_{r}\right) f(x) \mathrm{d} x-\left(\frac{2 b_{H}+e_{H}}{2}\right)+\frac{k}{2}\right]+\mu\left(\left(\frac{b_{H}+e_{H}}{2}\right)\right)-\gamma\left(\left(\frac{b_{H}+e_{L}}{2}\right)\right), \\
\frac{\partial L}{\partial b_{L}} & =(1-v)\left[-\frac{1}{2} \int_{Z_{L}}^{a}\left(p-c_{n}\right) f(x) \mathrm{d} x+\frac{1}{2} \int_{Z_{L}}^{a}\left(p-c_{r}\right) f(x) \mathrm{d} x-\left(\frac{2 b_{L}+e_{L}}{2}\right)+\frac{k}{2}\right]+\lambda\left(\frac{b_{L}+e_{L}}{2}\right)-\mu\left(\frac{b_{L}+e_{H}}{2}\right)+\gamma\left(\frac{b_{L}+e_{L}}{2}\right), \\
\frac{\partial L}{\partial T_{H}} & =v-\mu+\gamma=0, \\
\frac{\partial L}{\partial T_{L}} & =(1-v)-\lambda+\mu-\gamma=0 .
\end{aligned}
$$

After solving the optimal conditions of $K-T$ we get $\lambda=$ 1 and $\mu=v+\gamma$ which shows $\lambda>0$ and $\mu>0$. Further, we acquire $\gamma=0$.

(Disproof: Assume $\gamma>0$. According to $K-T$ conditions, the correspondent inequality equation (A.51) must be equality. Similarly, $\mu>0$ means constraint equation (A.50) is equality. So, we have $b_{H}=b_{L}$ and $T_{H}=T_{L}$ from the two constraints equations (A.50) and (A.51). At this time, the third-party collector faces the same contracts when he chooses $H$ contract or $L$ contract; thus, the contracts are mixed up. However, the collector who chooses different contracts is intermingled and harms the interests of enterprises under the mixed-up contracts. So, the assumption $\gamma>0$ is not provided and we obtain $\gamma=0$.)

Taking $\lambda=1, \mu=v$, and $\gamma=0$ into the optimal conditions of $K-T$, we can acquire

$$
\begin{aligned}
\frac{\partial L}{\partial b_{H}}= & v\left[-\frac{1}{2}\left(p-c_{n}\right) \int_{Z_{H}}^{a} f(x) \mathrm{d} x+\left(p-c_{r}\right) \frac{1}{2} \int_{Z_{H}}^{a} f(x) \mathrm{d} x-\frac{b_{H}}{2}+\frac{k}{2}\right]=0, \\
\frac{\partial L}{\partial b_{L}}= & -\frac{1}{2}\left(p-c_{n}\right) \int_{Z_{L}}^{a} f(x) \mathrm{d} x+\left(p-c_{r}\right) \frac{1}{2} \int_{Z_{L}}^{a} f(x) \mathrm{d} x-\frac{b_{L}}{2}+\frac{k}{2} \\
& -v\left[-\frac{1}{2}\left(p-c_{n}\right) \int_{Z_{L}}^{a} f(x) \mathrm{d} x+\left(p-c_{r}\right) \frac{1}{2} \int_{Z_{L}}^{a} f(x) \mathrm{d} x-\frac{b_{L}}{2}+\frac{k}{2}+\frac{e_{H}-e_{L}}{2}\right]=0 .
\end{aligned}
$$

Taking function $f(x)=\left\{\begin{array}{ll}1 / a, & x \in(0, a), \\ 0, & \text { otherwise, }\end{array}\right.$ as well as formulas $Z_{H}=e_{H}+r_{H H}-\phi+p$ and $Z_{L}=e_{L}+r_{L L}-\phi+p$ into the above two formulas, we solve out equations (A.65) and (A.66): 


$$
\begin{aligned}
& b_{H}^{* *}=\frac{\Delta\left(2 a-e_{H}+2 \phi-2 p\right)+2 a k}{2 a+\Delta}, \\
& b_{L}^{* *}=\frac{\Delta\left(2 a-e_{L}+2 \phi-2 p\right)+2 a\left(k-e_{L}\right)}{\Delta+2 a}+\frac{2 a\left(e_{L}-v e_{H}\right)}{(1-v)(\Delta+2 a)} .
\end{aligned}
$$

Solving $E\left(\pi_{r L L}\right)=\left(b_{L}-r_{L L}\right)\left(e_{L}+r_{L L}\right)-\left(e_{L}^{2} / 4\right)-T_{L}=$ $\left(\left(b_{L}+e_{L}\right) / 2\right)^{2}-\left(e_{L}^{2} / 4\right)-T_{L}=0$, we obtain

$$
T_{L}^{* *}=\frac{\left(b_{L}^{* *}+e_{L}\right)^{2}-e_{L}^{2}}{4}-\pi_{r}^{0} .
$$

Similarly, because $\mu>0$, equation (A.50) is equality.

$$
\begin{aligned}
E\left(\pi_{r H H}\right)= & \left(b_{H}-r_{H H}\right)\left(e_{H}+r_{H H}\right)-\frac{e_{H}^{2}}{4}-T_{H} \\
= & \left(b_{L}-r_{H L}\right) \\
& \left(e_{H}+r_{H L}\right)-\frac{e_{H}^{2}}{4}-T_{L}=E\left(\pi_{r H L}\right) .
\end{aligned}
$$

Thus, $\quad\left(\left(b_{H}+e_{H}\right) /(2)\right)^{2}-\left(e_{H}^{2} / 4\right)-T_{H}=\left(\left(b_{L}+e_{H}\right)\right.$ $/(2))^{2}-\left(e_{H}^{2} / 4\right)-T_{L}$; we find

$$
T_{H}^{* *}=\frac{\left(b_{H}^{* *}+e_{H}\right)^{2}-\left(b_{L}^{* *}+e_{H}\right)^{2}}{4}+T_{L}^{* *} \text {. }
$$

\section{Data Availability}

No data were used to support this study.

\section{Conflicts of Interest}

The authors declare that they have no conflicts of interest.

\section{References}

[1] J. Li, F. Tao, Y. Cheng, and L. Zhao, "Big data in product lifecycle management," The International Journal of Advanced Manufacturing Technology, vol. 81, no. 1-4, pp. 667-684, 2015.

[2] S. Yoo, D. Kim, and M. Park, "Pricing and return policy under various supply contracts in a closed-loop supply chain," International Journal of Production Research, vol. 53, no. 1, pp. 106-126, 2015.

[3] V. Jayaraman, V. D. R. Guide, and R. Srivastava, "A closedloop logistics model for remanufacturing," Journal of the Operational Research Society, vol. 50, no. 5, pp. 497-508, 1999.

[4] G. Ferrer and J. M. Swaminathan, "Managing new and remanufactured products," Management Science, vol. 52, no. 1, pp. 15-26, 2006.

[5] V. D. R. G. Jr and L. N. V. Wassenhove, "Or forum-the evolution of closed-loop supply chain research," Oper. Res., vol. 57, no. 1, pp. 10-18, 2009.

[6] A. A. Taleizadeh, M. S. Moshtagh, and I. Moon, "Pricing, product quality, and collection optimization in a decentralized closed-loop supply chain with different channel structures: game theoretical approach," Journal of Cleaner Production, vol. 189, pp. 406-431, 2018.

[7] R. C. Savaskan, S. Bhattacharya, and L. N. Van Wassenhove, "Closed-loop Supply Chain Models with Product
Remanufacturing," Management Science, vol. 50, no. 2, pp. 239-252, 2004.

[8] M. Huang, M. Song, L. H. Lee, and W. K. Ching, "Analysis for strategy of closed-loop supply chain with dual recycling channel," International Journal of Production Economics, vol. 144, no. 2, pp. 510-520, 2013.

[9] X. Chu, Q. Zhong, and X. Li, "Reverse channel selection decisions with a joint third-party recycler," International Journal of Production Research, vol. 5, pp. 1-13, 2018.

[10] S. Hosseini-Motlagh, M. Nematollahi, M. Johari, and M. Choi, "reverse supply chain systems coordination across multiple links with duopolistic third party collectors," IEEE Transactions on Systems, Man, and Cybernetics: Systems, vol. 99, pp. 1-12, 2019.

[11] X. Hong, L. Xu, P. Du, and W. Wang, "Joint advertising, pricing and collection decisions in a closed-loop supply chain," International Journal of Production Economics, vol. 167, pp. 12-22, 2015.

[12] P. D. Partha and M. G. Christopher, "Information sharing and coordination mechanisms for managing uncertainty in supply chains: a simulation study," International Journal of Production Research, vol. 49, no. 3, pp. 765-803, 2011.

[13] T. Li and H. Zhang, "Information sharing in a supply chain with a make-to-stock manufacturer," Omega, vol. 50, pp. 115-125, 2015.

[14] X. Li, Y. Li, and K. Govindan, "An incentive model for closedloop supply chain under the EPR law," Journal of the Operational Research Society, vol. 65, no. 1, pp. 88-96, 2014.

[15] W. Wang, Y. Zhang, Y. Li, X. Zhao, and M. Cheng, "Closedloop supply chains under reward-penalty mechanism: retailer collection and asymmetric information," Journal of Cleaner Production, vol. 142, pp. 3938-3955, 2017.

[16] B. C. Giri and S. Sharma, "Optimal production policy for a closed-loop hybrid system with uncertain demand and return under supply disruption," Journal of Cleaner Production, vol. 112, no. 3, pp. 2015-2028, 2016.

[17] P. D. Giovanni and G. Zaccour, "A two-period game of a closed-loop supply chain," European Journal of Operational Research, vol. 232, no. 1, pp. 22-40, 2014.

[18] N Wan and D Hong, "The impacts of subsidies policies and transfer pricing policies on the closed-loop supply chain with dual collection channels," Journal of Cleaner Production, vol. 224, pp. 881-891, 2019.

[19] D. Wang, Z. Wang, B. Zhang, and L. Zhu, "Vendor-managed inventory supply chain coordination based on commitmentpenalty contracts with bilateral asymmetric information," Enterprise Information Systems, vol. 5, pp. 1-18, 2020.

[20] B. Zheng, J. Chu, and L. Jin, "Recycling channel selection and coordination in dual sales channel closed-loop supply chains," Applied Mathematical Modelling, vol. 95, pp. 484-502, 2021.

[21] C. J. Corbett and C. S. Tang, "Designing supply contracts: contract type and information asymmetry," Management Science, vol. 50, no. 4, pp. 550-559, 1999.

[22] P. Zhang, Y. Xiong, and Z. Xiong, "Coordination of a dualchannel Supply Chain after Demand or Production Cost Disruptions," International Journal of Production Research, vol. 53, no. 10, pp. 3141-3160, 2014.

[23] P. Ma, J. Shang, and H. Wang, "Enhancing corporate social responsibility: contract design under information asymmetry," Omega, vol. 67, pp. 19-30, 2017.

[24] S. Zhang and J. Zhang, "Contract preference with stochastic cost learning in a two-period supply chain under asymmetric information," International Journal of Production Economics, vol. 196, pp. 226-247, 2018. 
[25] W. Wang, S. Zhou, M. Zhang, H. Sun, and L. He, "A closedloop supply chain with competitive dual collection channel under asymmetric information and reward-penalty mechanism," Sustainability, vol. 10, no. 7, p. 2131, 2018.

[26] X. Sun, W. Tang, and J. Chen, "Manufacturer encroachment with production cost reduction under asymmetric information," Transportation Research Part E: Logistics and Transportation Review, vol. 128, pp. 191-211, 2019.

[27] N. Wang, Y. Song, Q. He, and T. Jia, "Competitive dualcollecting regarding consumer behavior and coordination in closed-loop supply chain," Computers \& Industrial Engineering, vol. 144, Article ID 106481, 2020.

[28] L. Xie and J. Ma, "Study the complexity and control of the recycling-supply chain of china's color TVs market based on the government subsidy," Commun. Nonlinear. Sci. Numer. Simulat.vol. 38, pp. 102-116, 2016.

[29] S. Rahman and N. Subramanian, "Factors for implementing end-of-life computer recycling operations in reverse supply chains," International Journal of Production Economics, vol. 140, no. 1, pp. 239-248, 2012.

[30] X. Wang, H. Guo, R. Yan, and X. Wang, “Achieving optimal performance of supply chain under cost information asymmetry," Applied Mathematical Modelling, vol. 53, pp. 523-539, 2018.

[31] F. Zand, S. Yaghoubi, and S. Sadjadi, "Impacts of government direct limitation on pricing, greening activities and recycling management in an online to offline closed loop supply chain," Journal of Cleaner Production, vol. 215, pp. 1327-1340, 2019.

[32] C. Chen and M. Akmalul'Ulya, "Analyses of the rewardpenalty mechanism in green closed-loop supply chains with product remanufacturing," International Journal of Production Economics, vol. 210, pp. 211-223, 2019.

[33] W. Wang, S. Yang, L. Xu, and X. Yang, "Carrot/stick mechanisms for collection responsibility sharing in multi-tier closed-loop supply chain management," Transportation Research Part E: Logistics and Transportation Review, vol. 125, pp. 366-387, 2019.

[34] X. Zhang, Q. Li, Z. Liu, and C. Chang, "Optimal pricing and remanufacturing mode in a closed-loop supply chain of WEEE under government fund policy," Computers \& Industrial Engineering, vol. 151, Article ID 106951, 2021.

[35] N. Aras, V. Verter, and T. Boyaci, "Coordination and priority decisions in hybrid manufacturing/remanufacturing systems," Production and Operations Management, vol. 15, no. 4, pp. 528-543, 2006.

[36] X. Hong, K. Govindan, L. Xu, and P. Du, "Quantity and collection decisions in a closed-loop supply chain with technology licensing," European Journal of Operational Research, vol. 256, no. 3, 2017.

[37] J. Heydari, K. Govindan, and A. Jafari, "Reverse and closed loop supply chain coordination by considering government role. Transport. Part D: Transp,” Environ, vol. 52, pp. 379-398, 2017.

[38] S. Saha, S. P. Sarmah, and I. Moon, "Dual channel closed-loop supply chain coordination with a reward-driven remanufacturing policy," International Journal of Production Research, vol. 54, no. 5, pp. 1-15, 2016.

[39] J. Ding, W. Chen, and W. Wang, "Production and carbon emission reduction decisions for remanufacturing firms under carbon tax and take-back legislation," Computers \& Industrial Engineering, vol. 143, Article ID 106419, 2020.

[40] J. Ding, W. Chen, and S. Fu, "Optimal policy for remanufacturing firms with carbon options under service requirements," Journal of Systems Science and Systems Engineering, 2021. 